ARTICLE

\title{
c-FLIP is crucial for IL-7/IL-15-dependent NKp46+ ILC development and protection from intestinal inflammation in mice
}

\author{
Ute Bank $^{1,13}$, Katrin Deiser ${ }^{1,13}$, Carlos Plaza-Sirvent ${ }^{1,2}$, Lisa Osbelt ${ }^{3,4}$, Amelie Witte ${ }^{1}$, Laura Knop ${ }^{1}$, \\ Rebecca Labrenz (10 1, Robert Jänsch', Felix Richter ${ }^{1}$, Aindrila Biswas ${ }^{5}$, Ana C. Zenclussen ${ }^{6}$, Eric Vivier (1) 7,8,9, \\ Chiara Romagnani (10) 10,11, Anja A. Kühl ${ }^{12}$, Ildiko R. Dunay ${ }^{5}$, Till Strowig (1) 4, Ingo Schmitz (D) ${ }^{1,2,14}$ \& \\ Thomas Schüler (1,14凶
}

NKp46+ innate lymphoid cells (ILC) modulate tissue homeostasis and anti-microbial immune responses. ILC development and function are regulated by cytokines such as Interleukin (IL) -7 and IL-15. However, the ILC-intrinsic pathways translating cytokine signals into developmental programs are largely unknown. Here we show that the anti-apoptotic molecule cellular FLICE-like inhibitory protein (c-FLIP) is crucial for the generation of IL-7/IL-15dependent $\mathrm{NKp} 46^{+} \mathrm{ILC1}$, including conventional natural killer (cNK) cells, and ILC3. Cytokine-induced phosphorylation of signal transducer and activator of transcription 5 (STAT5) precedes up-regulation of c-FLIP, which protects developing NKp46+ ILC from TNF-induced apoptosis. NKp46+ ILC-specific inactivation of c-FLIP leads to the loss of all IL7/IL-15-dependent NKp46+ ILC, thereby inducing early-onset chronic colitis and subsequently microbial dysbiosis; meanwhile, the depletion of $\mathrm{cNK}$, but not NKp46+ ILC1/3, aggravates experimental colitis. In summary, our data demonstrate a non-redundant function of c-FLIP for the generation of NKp46+ ILC, which protect T/B lymphocyte-sufficient mice from intestinal inflammation.

\footnotetext{
${ }^{1}$ Institute of Molecular and Clinical Immunology, Medical Faculty, Otto-von-Guericke University, Magdeburg, Germany. ${ }^{2}$ Systems-Oriented Immunology and Inflammation Research Group, Department of Immune Control, Helmholtz Centre for Infection Research, Braunschweig, Germany. ${ }^{3}$ Institute of Medical Microbiology and Hospital Hygiene, Medical Faculty, Otto-von-Guericke University, Magdeburg, Germany. ${ }^{4}$ Microbial Immune Regulation Research Group, Helmholtz Centre for Infection Research, Braunschweig, Germany. ${ }^{5}$ Institute of Inflammation and Neurodegeneration, Medical Faculty, Otto-von-Guericke University, Magdeburg, Germany. ${ }^{6}$ Experimental Obstetrics and Gynecology, Medical Faculty, Otto-von-Guericke University, Magdeburg, Germany. ${ }^{7}$ Centre d'Immunologie de Marseille-Luminy, Aix Marseille Université, Inserm, CNRS, Marseille, France. ${ }^{8}$ Service d'Immunologie, Hôpital de la Timone, Assistance Publique-Hôpitaux de Marseille, Marseille, France. ${ }^{9}$ Innate Pharma Research Labs., Innate Pharma, Marseille, France. ${ }^{10}$ Innate Immunity, German Rheumatism Research Center (DRFZ), Leibniz Association, Berlin, Germany. ${ }^{11}$ Medical Department I, Charité - University Medical Center Berlin, Berlin, Germany. ${ }^{12}$ Charité - Universitätsmedizin Berlin, corporate member of Freie Universität Berlin, Humboldt Universität zu Berlin, and Berlin Institute of Health, iPATH, Berlin, Germany. ${ }^{13}$ These authors contributed equally: Ute Bank, Katrin Deiser. ${ }^{14}$ These authors jointly supervised this work: Ingo Schmitz, Thomas Schüler. ${ }^{凶}$ email: thomas.schueler@med.ovgu.de
} 
nnate lymphoid cells (ILC) modulate immune responses and tissue homeostasis at multiple levels. Reminiscent to the classification of helper T cell subsets, different types of ILC can be distinguished based on their cytokine and transcription factor expression profiles ${ }^{1}$. Type $1 \mathrm{NKp}^{+} 6^{+} \mathrm{T}$-bet ${ }^{+}$(ILC1) produce Interferon- $\gamma$ (IFN- $\gamma)$ and contribute e.g. to Toxoplasma gondii clearance $^{2}$. Conventional $\mathrm{NK}$ cells $(\mathrm{cNK})$ represent a subpopulation of ILC1, which is characterized by the co-expression of T-bet and Eomes ${ }^{1}$. Distinct from T-bet ${ }^{+}$Eomes $^{-}$helper-like ILC1, cNK synthesize cytotoxic molecules, such as perforins and granzymes as well as death ligands (DLs) like tumor necrosis factor a (TNF), TNF-related apoptosis inducing ligand (TRAIL) and FAS ligand (FASL) enabling them to induce target cell apoptosis $^{3}$. On the contrary, NKp46- GATA3 ${ }^{+}$ILC2 produce Interleukin (IL) -5 and IL-13 and promote helminth rejection ${ }^{4}$, while NKp46 ${ }^{+/-} \mathrm{ROR}_{\mathrm{t}}{ }^{+}$ILC3 support anti-bacterial responses in mice lacking $\mathrm{T}$ and $\mathrm{B}$ lymphocytes ${ }^{5}$. Furthermore, ILC3 regulate tissue homeostasis and regeneration, e.g., in the intestine and lung ${ }^{6}$. For example, ILC3-derived IL-22 promotes intestinal epithelial stem cell regeneration ${ }^{7}$, providing an explanation for the tissue-protective effect of IL-22 in the course of dextran sodium sulfate (DSS)-induced colitis ${ }^{8}$.

Most studies defining immune modulatory and tissue protective functions of NKp46+ ${ }^{+}$ILC3 were performed with T and $\mathrm{B}$ lymphocyte (T/B)-deficient mice. However, recent evidence suggests that T lymphocytes can compensate for the lack of $\mathrm{NKp}^{4} 6^{+}$ ILC $3^{9-11}$. Whether the degree of compensation is determined by the experimental system or whether ILC3 are generally of limited importance in a T/B-competent host is still unclear.

Developing and mature ILC express a multitude of cytokine receptors including those for IL-15 and IL- $7^{12}$. Both cytokines signal via signal transducer and activator of transcription 5 (STAT5) $^{13}$ and are crucial for ILC development and survival ${ }^{2,14}$. For example, IL-15 withdrawal activates the intrinsic apoptosis pathway in $\mathrm{cNK}^{15}$. This is associated with the failure to repress expression of the pro-apoptotic molecule Bcl2-interacting mediator of cell death (Bim), the loss of anti-apoptotic myeloid cell leukemia-1 (Mcl-1) and the subsequent death of $\mathrm{cNK}^{15}$. IL-7 and IL-15 are produced by e.g., stromal fibroblasts ${ }^{16,17}$ and intestinal epithelial cells (IEC) ${ }^{6,18}$, which create the cytokine environment required for the maintenance of ILC homeostasis and function ${ }^{12}$. However, ILC-intrinsic signaling molecules required for the conversion of environmental cues into developmental programs are largely unknown. In order to identify such signaling molecules and to define unique functions of intestinal NKp46 ${ }^{+}$ILC, we made use of NKp $46^{{ }^{i C r e}}$ mice ${ }^{19}$. These mice are T/B-competent and allow targeted gene inactivation in $\mathrm{NKp} 46^{+}$ILC.

Here, we show that the anti-apoptotic molecule cellular FLICElike inhibitory protein (c-FLIP), a master regulator of the extrinsic apoptosis pathway ${ }^{20}$, is a target of STAT5-dependent cytokine signaling in $\mathrm{NKp} 46^{+}$ILC. The NKp46-specific inactivation of cFLIP leads to the loss of NKp46 ${ }^{+}$ILC1, including cNK, and ILC3 without affecting $\mathrm{T}$ and $\mathrm{B}$ lymphocyte homeostasis. Furthermore, we provide evidence that cytokine-dependent c-FLIP induction prevents a TNF-induced suicide program in developing $\mathrm{NKp}_{4}{ }^{+}$ ILC. Finally, we define a non-redundant function of c-FLIPdependent $\mathrm{NKp} 46^{+} \mathrm{cNK}$ in the intestine. Specifically, different from mice only lacking NKp46 ${ }^{+}$ILC3, mice lacking NKp46 ${ }^{+} \mathrm{cNK}$ fail to recover from acute colitis and develop early signs of chronic disease. Furthermore, although not affecting the establishment of a normal commensal microbiota in the steady state, $\mathrm{NKp} 46^{+}$ILC counteract inflammation-associated commensal dysbiosis. In summary, we show that the anti-apoptotic molecule c-FLIP is crucial for the cytokine-dependent development of $\mathrm{NKp} 46^{+} \mathrm{cNK} / \mathrm{ILC} 1$ and ILC3 and subsequent protection from intestinal inflammation by $\mathrm{cNK}$, a function that cannot be compensated by other immune cells.

\section{Results}

c-FLIP is essential for the development of NKp46 ${ }^{+}$ILC. c-FLIP is a master regulator of the extrinsic apoptosis pathway ${ }^{20}$ and protects immune and non-immune cells from caspase 8dependent apoptosis 21,22 . The expression of c-FLIP is crucial for $\mathrm{T}$ cell development ${ }^{23}$ and is up-regulated by activated human and mouse T cells ${ }^{24}$. IL-15 is crucial for the development of T-bet ${ }^{+}$ ILC1 including $\mathrm{CNK}^{25,26}$. Whether and how the external apoptosis pathway is involved in IL-15-dependent ILC development and function was unclear. In order to identify a functional link between IL-15 signaling and Cflar (encoding c-FLIP) gene regulation, $\mathrm{CD}^{-} \mathrm{NK} 1.1^{+} \mathrm{NKp} 46^{+}$ILC were purified from spleens of $\mathrm{C} 57 \mathrm{BL} / 6$ (B6) mice and cultured for $16 \mathrm{~h}$ in the presence or absence of IL-15. The murine Cflar gene encodes for two isoforms of c-FLIP, the long form c-FLIP $_{L}$ and the short Raji isoform c-FLIP ${ }_{\mathrm{R}}{ }^{27}$. Quantitative real-time PCR (RT-qPCR) revealed that $\mathrm{NKp} 46^{+}$ILC significantly up-regulate the mRNA of the long isoform c-FLIP $\mathrm{L}$, but not $\mathrm{c}-\mathrm{FLIP}_{\mathrm{R}}$, in response to IL-15 (Fig. 1a). Elevated Cflar gene activity correlated with the phosphorylation of STAT5 and elevated c-FLIP protein levels (Fig. 1b). The blockade of STAT5 phosphorylation by pimozide led to impaired IL-15dependent c-FLIP up-regulation (Fig. 1b). Hence, c-FLIP is a target of STAT5-dependent IL-15 signaling in mature NKp46 ${ }^{+}$ILC.

Next, we investigated whether c-FLIP is required for the development of IL-15/STAT5-dependent NKp46 ${ }^{+}$ILC. For this purpose, conditional STAT5 (STAT5 $5^{\mathrm{f} / \mathrm{fl}}$ ) and c-FLIP (c-FLIPfl/fl) knockout mice were crossed to $\mathrm{NKp} 46^{\mathrm{iCre}}$-transgenic mice to generate $\mathrm{NK}^{\Delta \mathrm{STAT5}}$ and $\mathrm{NK}^{\Delta \mathrm{c} \text {-FLIP }}$ mice, respectively. $\mathrm{NKp} 46^{\mathrm{iCre}}$ transgenic mice harboring wildtype alleles of the respective target gene served as NK ${ }^{\mathrm{WT}}$ controls. Similar to IL-15-deficient (IL-15 ${ }^{-1-}$ ) and IL-15 receptor $\alpha$-deficient (IL-15R-/-) mice, numbers of splenic $\mathrm{NKp} 46^{+}$ILC were strongly reduced in $\mathrm{NK}^{\Delta \mathrm{STAT5}}$ and $\mathrm{NK}^{\Delta \mathrm{c}-\mathrm{FLIP}}$ mice (Fig. 1c). IL-15 deprivation causes cNK apoptosis ${ }^{28}$. Accordingly, residual splenic IL-15 $-1-$ and IL-15R $\mathrm{R}^{-1-} \mathrm{NKp} 46^{+}$ILC showed increased rates of caspase-3/7 activity (Fig. 1d). The frequencies of NKp46 ${ }^{+}$ILC expressing active caspase-3/7 were also elevated in NK ${ }^{\Delta S T A T 5}$ and NK ${ }^{\Delta c-F L I P}$ mice (Fig. 1d).

Furthermore, we observed increased frequencies of immature double negative (DN) NK1.1- ${ }^{-} \mathrm{NK} 46^{-}$and single positive (SP) $\mathrm{NK} 1.1^{+} \mathrm{NKp} 46^{-}$cells in conjunction with a reduced abundance of double positive (DP) NK1.1 $1^{+} \mathrm{NKp} 46^{+}$ILC in spleens and bone marrow (BM) of IL-15 $1-$, IL-15R $\mathrm{R}^{-/-}, \mathrm{NK}^{\Delta \mathrm{STAT5}}$, and NK $\mathrm{N}^{\Delta \mathrm{c}-\mathrm{FLIP}}$ mice (Fig. 1e, f). Of note, the development of other immune cells remained unaltered in $\mathrm{NK}^{\Delta \mathrm{c} \text {-FLIP }}$ mice (Supplementary Fig. 1). Altogether, our results demonstrate that c-FLIP is crucial for the IL-15/STAT5-dependent development of NKp46 ${ }^{+}$ILC in the BM and their survival in the periphery.

c-FLIP protects ILC precursors from TNF-induced apoptosis. ILC1 produce effector molecules such as IFN- $\gamma$ and DLs like TNF and TRAIL ${ }^{29}$. In the absence of c-FLIP, human cNK become sensitive to their own effector molecules and undergo apoptosis ${ }^{30}$. We therefore hypothesized that the loss of $\mathrm{NKp} 46^{+}$ILC in $\mathrm{NK}^{\Delta \mathrm{c}-\mathrm{FLIP}}$ mice resulted from death receptor (DR)-induced apoptosis during ILC1 development. To elucidate whether effector genes are activated in BM ILC, we first analyzed IFN- $\gamma$ reporter mice expressing eYFP under control of the Ifng promoter. As shown in Fig. 2a, Ifng promoter activity increased from the $\mathrm{NK} 1.1^{-} \mathrm{NKp} 46^{-} \mathrm{DN}$ to the $\mathrm{NK} 1.1^{+} \mathrm{NKp} 46^{-} \mathrm{SP}$ stage and reached its maximum at the NK1.1 $1^{+} \mathrm{NKp} 46^{+}$DP stage. Similarly, TNF mRNA levels increased progressively from the DN to the DP stage (Fig. 2b). Of note, DR mRNAs for TRAIL-R2, FAS and TNF-RI were also detectable throughout ILC development, the latter being particularly high in DP cells (Fig. 2c). In addition, c-FLIP $_{\mathrm{L}}$ and $\mathrm{c}-$ FLIP $_{\mathrm{R}}$ mRNAs were expressed at all developmental 
a

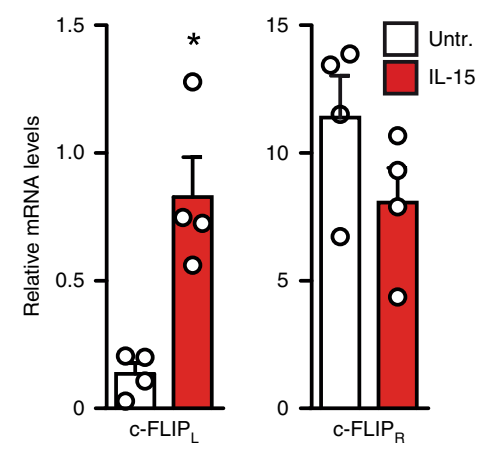

b

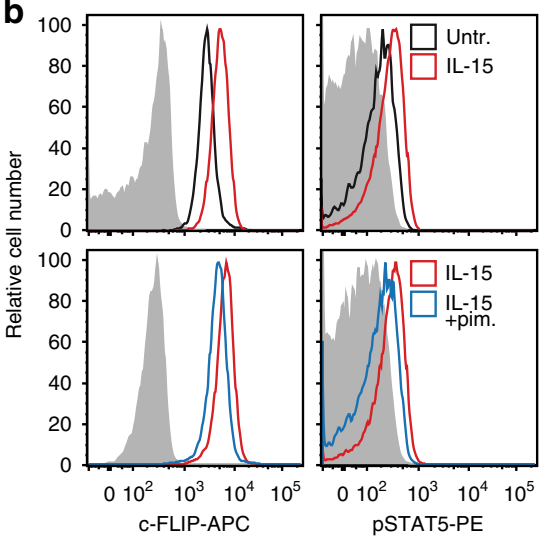

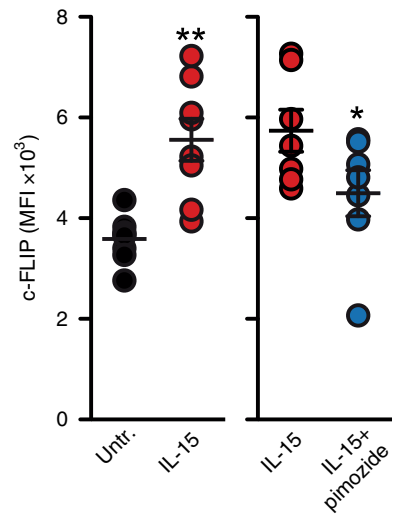
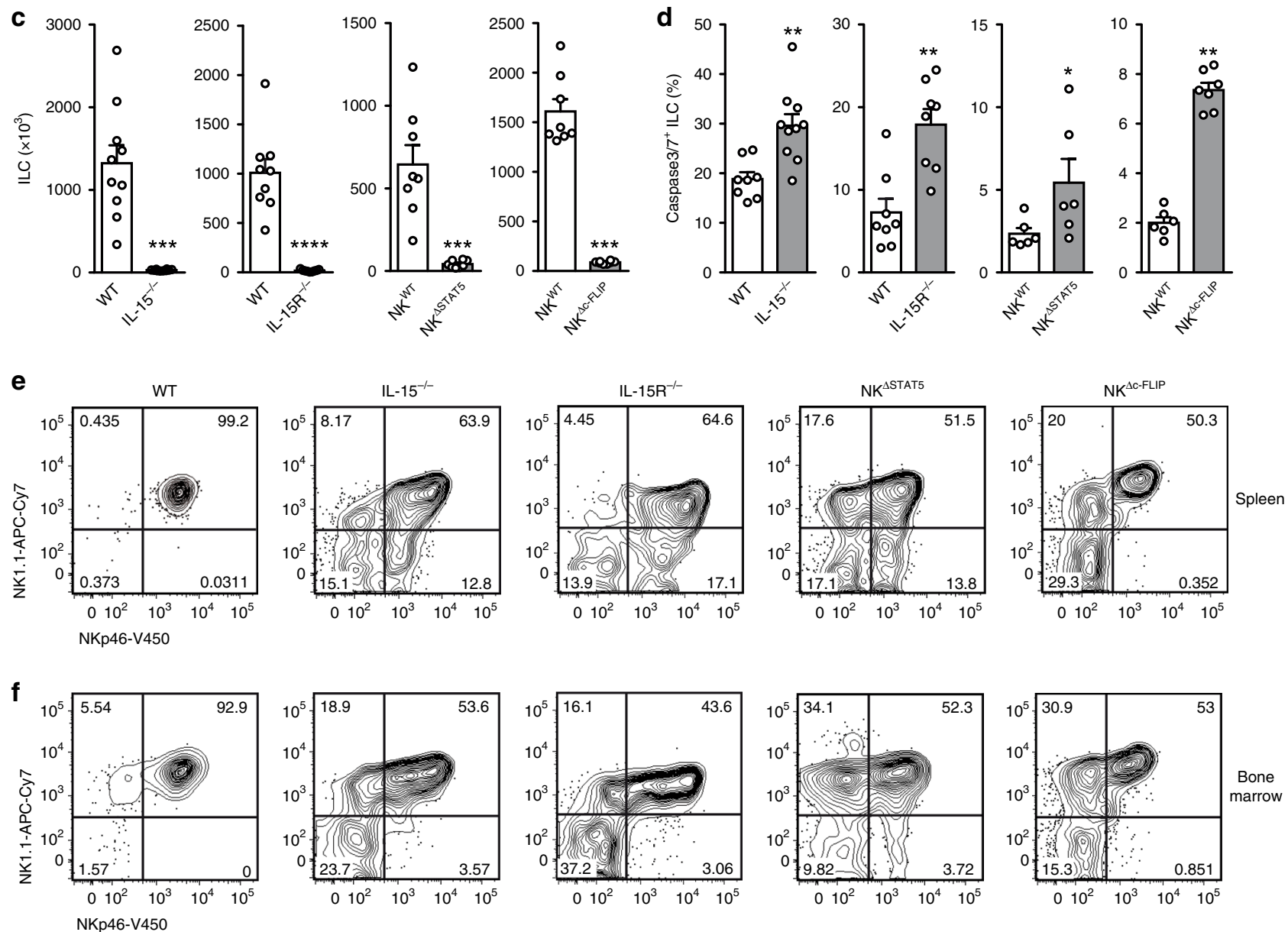

Fig. 1 c-FLIP is crucial for IL-15-dependent ILC development. a NK1.1+NKp46+ ILC were FACS-purified from spleens of C57BL/6 (B6) wild type (WT) mice and incubated for $16 \mathrm{~h}$ w/wo IL-15. c-FLIP and c-FLIP $R$ mRNA levels were quantified by RT-qPCR. Data are from four independent experiments. b B6 splenocytes were cultured for $16 \mathrm{~h}$ in the presence (red) or absence of IL-15 (black; upper row). Alternatively, cells were cultured for $16 \mathrm{~h}$ in the presence of IL-15 with (blue) or without the STAT5 inhibitor pimozide (red; bottom row). Relative levels of c-FLIP and phosphorylated STAT5 (pSTAT5) were determined by flow cytometry. Shown are representative histograms (fluorescence minus one controls in gray) after gating on Lin-CD122+NK1.1 ${ }^{+} \mathrm{NKp} 46^{+}$ILC. Graphs show mean fluorescence intensities (MFI) from 2-3 independent experiments with a total of 7-8 mice per group. c-e Cells from spleen and $\mathbf{f}$ BM of the indicated mouse lines were analyzed by flow cytometry. $\mathbf{c}-\mathbf{f}$ After gating on $\mathrm{Lin}^{-} \mathrm{CD}_{122^{+}}$cells, $\mathbf{c}$ absolute cell numbers $(n=8-10)$ and $\mathbf{d}$ frequencies of active caspase3/7+ apoptotic NK1.1+NKp46+ ILC were determined $(n=6-10)$. e, $\mathbf{f}$ Shown are representative contour plots from at least two independent experiments with a total of e 8-10 or $\mathbf{f}$ 6-10 mice per group. Numbers indicate percentages. a-d Data represent mean $+/ \pm$ SEM. Source data are provided as source data file; ${ }^{\star} p \leq 0.05 ;{ }^{\star \star} p \leq 0.005 ;{ }^{\star \star \star} p \leq 0.001 ;{ }^{\star \star \star \star} p \leq 0.0001$. a, c, d Two-tailed Mann-Whitney $U$ test; $\mathbf{b}$ two-tailed Wilcoxon matched-pairs signed rank test. 
a
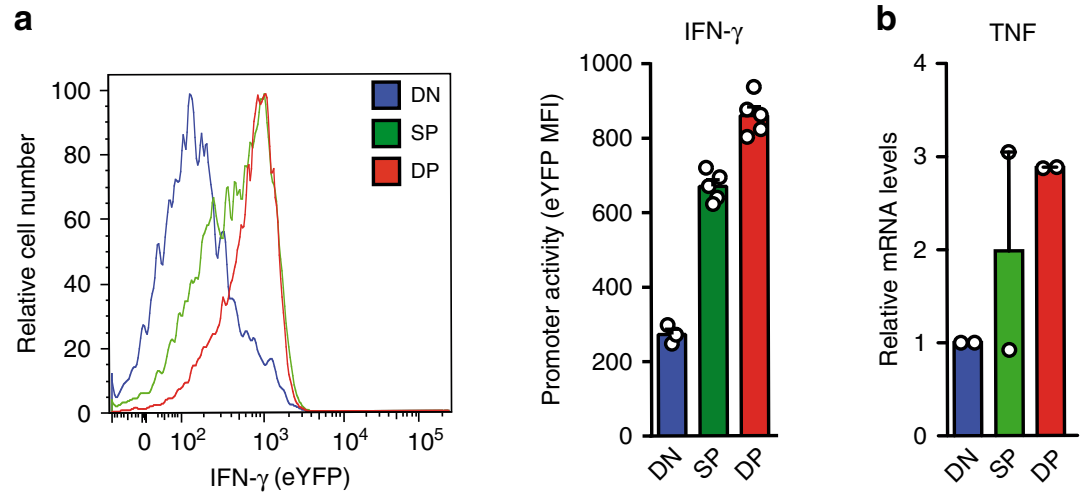

C
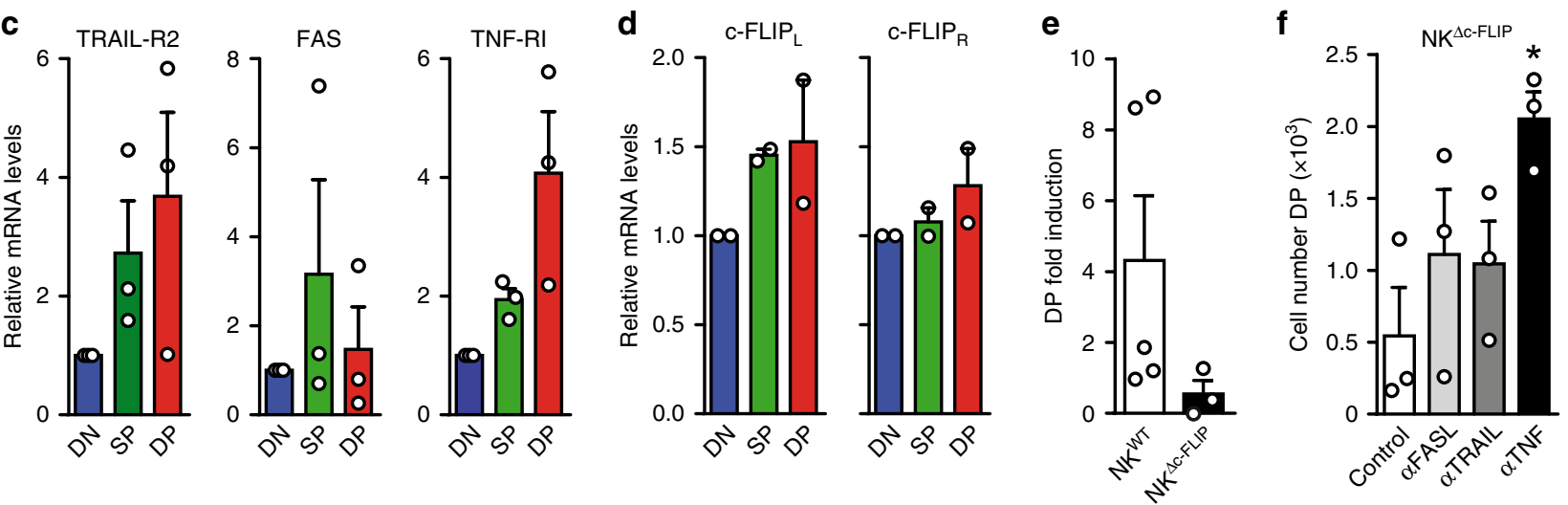

Fig. 2 The generation of NKp46 ${ }^{+}$ILC requires c-FLIP-mediated protection from TNF-induced apoptosis. a To determine Ifng promoter activity in unstimulated ILC precursors, freshly isolated BM cells from eYFP-transgenic IFN- $\gamma$ reporter mice were analyzed by flow cytometry. Mean fluorescence intensities (MFI) were determined for eYFP after gating on $\mathrm{Lin}^{-} \mathrm{CD} 122^{+} \mathrm{DN}, \mathrm{SP}$, and DP cells. Representative histograms and pooled results (bar diagrams, mean + SEM) from two independent experiments with a total of five mice are shown ( $D N=3$ data points). $\mathbf{b}-\mathbf{d} \mathrm{Lin}^{-} \mathrm{CD} 122^{+} \mathrm{DN}, \mathrm{SP}$, and $\mathrm{DP}$ cells were FACS-purified from BM of B6 mice and the indicated mRNAs were quantified by RT-qPCR. mRNA levels of DN cells were set to 1 and all other values were calculated in relation. Shown are pooled results (mean $+\mathrm{SEM}$ ) from $\mathbf{b}, \mathbf{d}$ two and $\mathbf{c}$ three independent experiments. e, $\mathbf{f} \mathrm{Lin}^{-} \mathrm{CD} 122^{+} \mathrm{DN}$ cells from e NKWT and NK ${ }^{\Delta c-F L I P}$ mice or $\mathbf{f} N K^{\Delta c-F L I P}$ mice alone were enriched by FACS-sorting. $\mathbf{f}$ To block DR-function, $\alpha$ FASL, $\alpha$ TRAIL, or $\alpha$ TNF antibodies were added to the indicated cultures. e, f After 9 days of culture, numbers of viable DP cells were calculated in relation to those at day 0 . $\mathbf{f}$ Absolute cell numbers are shown. Data (mean + SEM) were pooled from 3-5 independent experiments. a-f Source data are provided as source data file; $\mathbf{e} \mathbf{f}^{\star} p \leq 0.05 ;{ }^{\star \star} p \leq 0.005 ;$ ${ }^{\star \star \star} p \leq 0.001 ;{ }^{\star \star \star \star} p \leq 0.0001$ (paired Student's $t$ test).

stages (Fig. 2d). Interestingly, only c-FLIP ${ }_{L}$ mRNA showed a maturation-associated increase (Fig. 2d) similar to TNF (Fig. 2b), TRAIL-R2 and TNF-RI (Fig. 2c).

In order to elucidate the impact of DLs on c-FLIP-dependent ILC development, we established an in vitro culture system. DN cells were enriched from $\mathrm{BM}$ of $\mathrm{NK}^{\mathrm{WT}}$ and $\mathrm{NK}^{\Delta \mathrm{c} \text {-FLIP }}$ mice and cultured for 9 days. In accordance with our in vivo data, the generation of DP cells was impaired in the absence of c-FLIP (Fig. 2e). Importantly, this effect could be recovered most effectively by the antibody-mediated blockade of TNF (Fig. 2f).

Together, our results demonstrate that TNF and TNF-RI upregulation are programmed events in the course of $\mathrm{NKp}^{-} 6^{+}$ILC development. The partial recovery of $\mathrm{NK}^{\Delta \mathrm{c}-\mathrm{FLIP}}$ ILC development by aTNF treatment strongly suggests that the cytokine-induced, STAT5-dependent up-regulation of c-FLIP ${ }_{L}$ (Fig. 1a, b) is crucial for protection of developing ILC from TNF-induced apoptosis.

IL-7- and IL-15-dependent intestinal NKp46 ${ }^{+}$ILC require cFLIP. The small intestine (SI) harbors NKp46 ${ }^{+}$T-bet ${ }^{+}$ILC1, including T-bet $^{+}$Eomes $^{+} \mathrm{cNK}$, as well as NKp46 ${ }^{-}$GATA3 $^{+}$ILC2 and $\mathrm{NKp} 46^{+/-} \mathrm{CD} 4^{+/-} \mathrm{ROR}_{\mathrm{t}} \mathrm{t}^{+} \mathrm{ILC}^{12}$. In order to analyze whether c-FLIP affects intestinal ILC homeostasis, leukocytes were isolated from the small intestinal lamina propria of $\mathrm{NK}^{\mathrm{WT}}$ and $\mathrm{NK}^{\Delta \mathrm{c} \text {-FLIP }}$ mice. The abundance of $\mathrm{NKp} 46^{+} \mathrm{NK} 1.1^{+}$ILC
(Fig. 3a, e) including T-bet ${ }^{+}$ILC1 (Fig. 3b, e), NK1.1 ${ }^{+}$Eomes $^{+}$ cNK (Fig. 3c, e) and NKp46 ${ }^{+}$ROR $\gamma \mathrm{t}^{+}$ILC3 (Fig. 3d, e) were strongly reduced in the $\mathrm{SI}$ of $\mathrm{NK}^{\Delta \mathrm{c}-\mathrm{FLIP}}$ mice. Importantly, numbers of $\mathrm{NKp} 46^{-} \mathrm{CD} 4^{+/-} \mathrm{ROR} \mathrm{t}^{+}$ILC3 (Fig. 3d, f) and NKp46- ${ }^{-}$SATA3 $^{+}$ILC2 (Fig. 3f) remained unaltered in $\mathrm{NK}^{\Delta \mathrm{c}-\mathrm{FLIP}}$ mice. Hence, $\mathrm{NK}^{\Delta \mathrm{c}-\mathrm{FLIP}}$ mice lack NKp46 ${ }^{+}$ILC but have normal numbers of NKp46- ILC in the SI. Similar data were obtained with $\mathrm{NK}^{\triangle \mathrm{STAT} 5}$ mice (Fig. $3 \mathrm{~g}, \mathrm{~h}$ ) further emphasizing the functional link between STAT5 and c-FLIP.

The development of cNK/ILC1 largely relies on IL-15 2,25,31 (Supplementary Fig. 2) rather than IL-7 signaling. The latter point is exemplified by the fact that $\mathrm{cNK}$ numbers in spleen and SI did not differ significantly between $\mathrm{RAG}^{-1-}$ and $\mathrm{RAG}^{-1-} \times$ IL-7R $\mathrm{R}^{-1-}$ mice (Fig. 3i, j). On the contrary, numbers of all other SI NKp46 ${ }^{+}$and NKp46 ${ }^{-}$ILC subsets were strongly reduced in $\mathrm{RAG}^{-1-} \times \mathrm{IL}^{-7 \mathrm{R}^{-/}-}$mice (Fig. $3 \mathrm{j}, \mathrm{k}$ ). IL-15 can partially compensate for the lack of IL-7R signaling ${ }^{32}$ providing an explanation for the survival of some residual ILC in RAG1 ${ }^{-1-} \times$ IL-7R $\mathrm{R}^{-1-}$ mice (Fig. 3j, k). Of note, this compensatory effect was less efficient for $\mathrm{NKp} 46^{+} \mathrm{ROR} \gamma \mathrm{t}^{+}$ILC3, which were more severely affected by the lack of IL-7R signaling than NKp46- ROR $\mathrm{t}^{+}$ILC3 (Fig. 31; lower panel).

IL-7R and IL-15R signaling converge at the level of STAT5 phosphorylation which precedes c-FLIP up-regulation (Fig. 1b). 
a
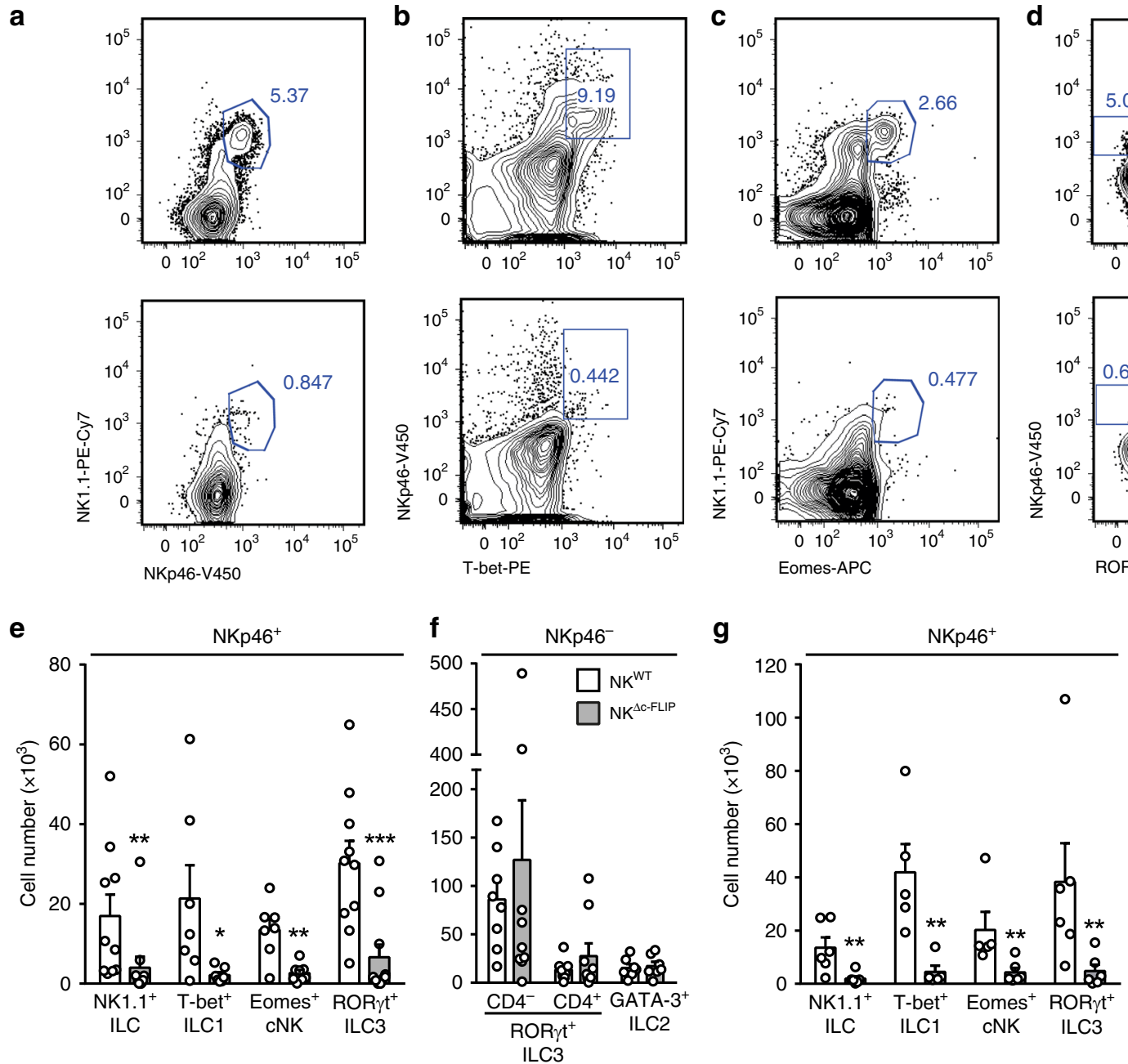

i

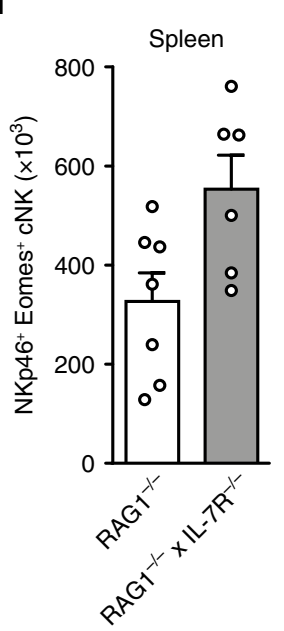

j
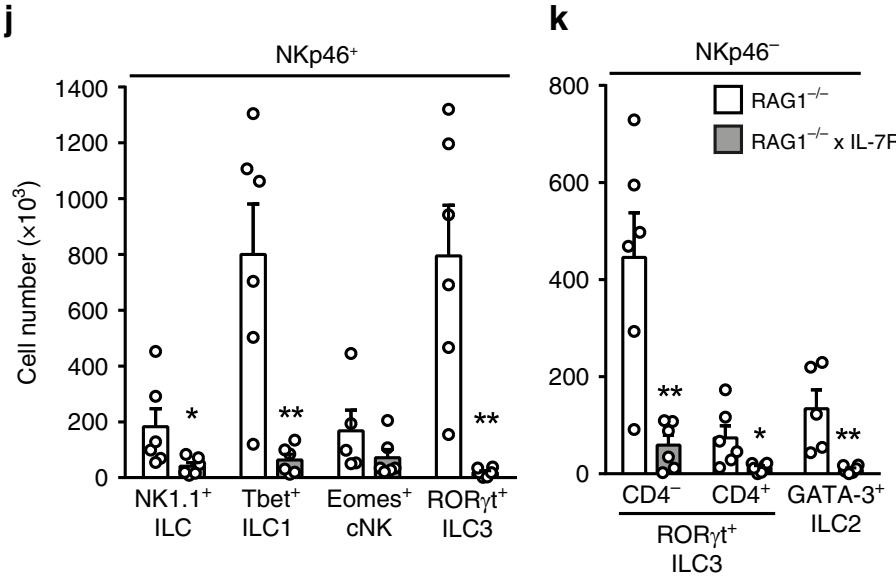
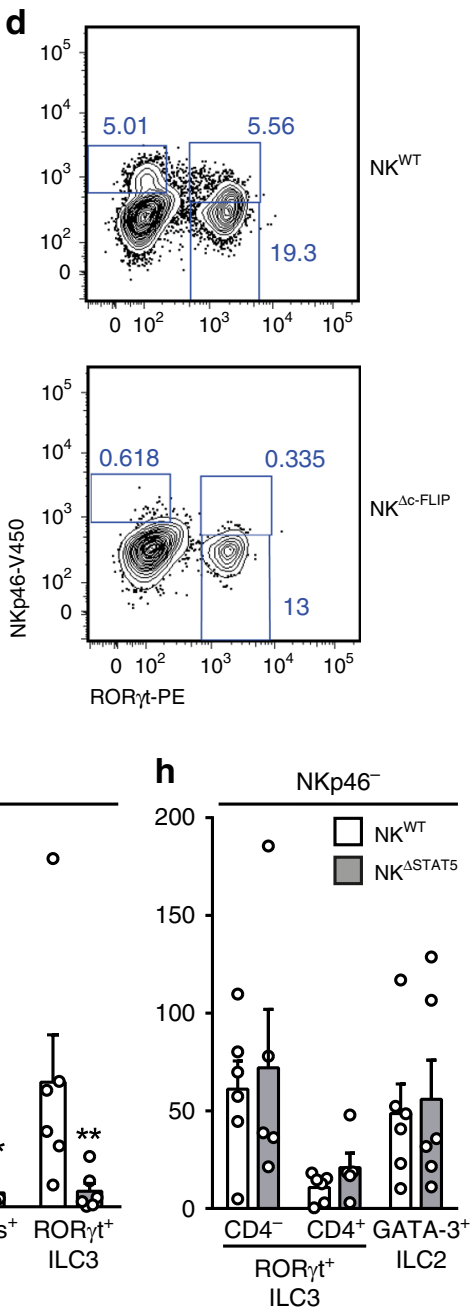

I
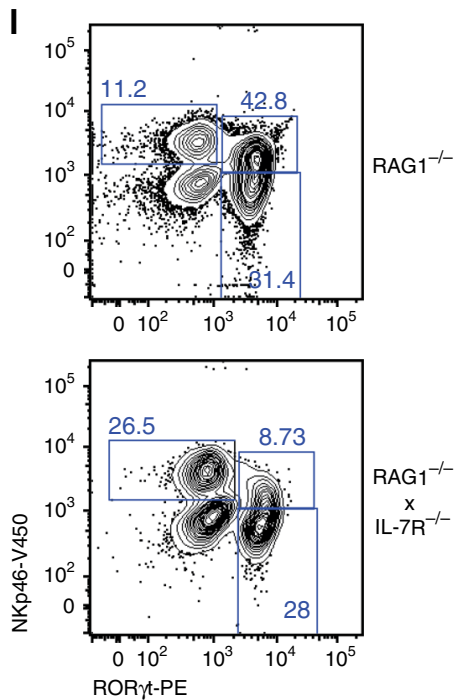

Fig. 3 NK ${ }^{\Delta c-F L I P}$ mice lack IL-7- and IL-15-dependent NKp46+ ILC in the small intestine. a-h and $\mathbf{j}-\mathbf{I}$ Leukocytes were isolated from the small intestinal (SI) lamina propria of a-f NK ${ }^{\Delta c-F L I P}, \mathbf{g}, \mathbf{h} N K^{\Delta S T A T 5}, \mathbf{j}-\mathbf{I} R A G 1^{-/-} \times I L-7 R^{-/-}$and respective control mice. i Spleen cells from RAG1-/- $\times$IL-7R-/- and RAG1 ${ }^{-/-}$mice were analyzed. $\mathbf{a}-\mathbf{h}$ and $\mathbf{j}-\mathbf{I}$ To discriminate between different subsets of NKp46 ${ }^{+}$(ILC: NK1.1 $1^{+}$; ILC1: T-bet ${ }^{+}$, cNK: Eomes ${ }^{+}$; ILC3: ROR $\gamma \mathrm{C}^{+}$) and NKp46- ILC (ILC3: RORyt ${ }^{+}$; ILC2: GATA3 ${ }^{+}$), cells were analyzed by flow cytometry after gating on Lin $^{-}{\text {CD } 45^{+}}^{+}$cells. e-k Absolute cell numbers are shown as mean + SEM. a-d and I Shown are representative contour plots and $\mathbf{e}-\mathbf{k}$ pooled results from 3 to 5 independent experiments with a total of e, f 10-11, $\mathbf{g}, \mathbf{h}$ 6, i 6-7 and $\mathbf{j}, \mathbf{k} 6$ mice per group. e For NKp46+ ILC, ILC1, CNK, and ILC3, 10-11, 7, 7-8, and 10-11 samples were analyzed, respectively. f For NKp46- CD4- ILC3, CD4+ ILC3 and ILC2, 8-9, 8-9 and 7 samples were analyzed, respectively. g, h 5-6, i 6-7, j, k 5-6 samples were analyzed for the indicated ILC subsets. a-d and I Numbers indicate percentages. e-k Source data are provided as source data file; ${ }^{\star} p \leq 0.05$; ${ }^{\star \star} p \leq 0.005$; ${ }^{\star \star \star} p \leq 0.001$; ${ }^{\star \star \star \star} p \leq 0.0001$ (two-tailed Mann-Whitney $U$ test). 
Hence, the simultaneous lack of IL-15- and IL-7-dependent $\mathrm{NKp}_{4} 6^{+}$ILC1 and ILC3 in $\mathrm{NK}^{\Delta \mathrm{c}-\mathrm{FLIP}}$ and $\mathrm{NK}^{\Delta \mathrm{STAT5}}$ mice strongly suggests that both cytokines promote ILC development and survival via the STAT5-dependent induction of c-FLIP.

c-FLIP-dependent NKp46 ${ }^{+}$ILC protect mice from acute colitis. Inflammatory bowel disease (IBD) is associated with pronounced changes in ILC1 and ILC3 frequencies and functions ${ }^{29}$. Whether and how the absence of NKp46 ${ }^{+}$ILC1 and ILC3 affects the course of IBD was unclear. In order to address this subject, $\mathrm{NK}^{\Delta \mathrm{c}-\mathrm{FLIP}}$ and control mice were treated with DSS for 5 days. The administration of DSS causes IEC damage, loss of epithelial integrity, innate immune cell activation, and results in IBD-like symptoms ${ }^{33}$. To monitor disease progression, relative body weight (Fig. 4a), feces consistency (Fig. 4b), and the degree of intestinal bleeding (Fig. 4c) were determined and the overall colitis score was calculated (Fig. 4d). As shown in Fig. $4 \mathrm{a}-\mathrm{d}$, disease severity was strongly increased in $\mathrm{NK}^{\Delta \mathrm{c} \text {-FLIP }}$ mice. Accordingly, the specific colon weight was strongly increased in $\mathrm{NK}^{\Delta \mathrm{c} \text {-FLIP }}$ mice indicating edema formation and increased cellularity (Fig. 4e). Furthermore, the colon length was significantly decreased in $\mathrm{NK}^{\Delta \mathrm{c} \text {-FLIP }}$ mice (Fig. $4 \mathrm{f}, \mathrm{g}$ ) and inflammationrelated alterations in tissue architecture were more pronounced (Fig. 4h). When colonic immune cell infiltrates were analyzed, we observed the almost complete absence of $\mathrm{NKp}^{+} 6^{+} \mathrm{NK} 1.1^{+}$ILC including T-bet ${ }^{+}$ILC1, Eomes ${ }^{+}$cNK and ROR $\gamma \mathrm{t}^{+}$ILC3 (Fig. 4i, j) in $\mathrm{NK}^{\Delta \mathrm{c} \text {-FLIP }}$ mice. On the contrary, numbers of $\mathrm{NKp} 46^{-}$ILC did not differ significantly between $\mathrm{NK}^{\Delta \mathrm{c}-\mathrm{FLIP}}$ and $\mathrm{NK}^{\mathrm{WT}}$ mice (Fig. 4k). Importantly, CD45 ${ }^{+} \mathrm{CD} 11 \mathrm{~b}^{+}$granulocytes, in particular pro-inflammatory $\mathrm{Ly} 6 \mathrm{C}^{+} \mathrm{Ly}_{6 \mathrm{G}} \mathrm{G}^{+}$neutrophils, rather than Ly6C ${ }^{-} \mathrm{Ly}_{6 \mathrm{G}} \mathrm{H}^{-1-}$ monocytes, accumulated more efficiently in the inflamed colon of $\mathrm{NK}^{\Delta \mathrm{c} \text {-FLIP }}$ mice (Fig. 4l, m). Thus, the lack of c-FLIP-dependent, NKp46 ${ }^{+}$ILC promotes acute colitis and cannot be compensated by $\mathrm{T}$ or $\mathrm{B}$ lymphocytes.

$\mathrm{NKp46}^{+}$ILC protect mice from early onset of chronic colitis. Repeated DSS administration causes chronic colitis ${ }^{33}$. Since it was unclear whether this is also affected by NKp46 $6^{+}$ILC, NK ${ }^{\mathrm{WT}}$ and $\mathrm{NK}^{\Delta \mathrm{c} \text {-FLIP }}$ mice were treated repetitively with DSS. In agreement with the results from the acute colitis model (Fig. $4 a-d$ ), disease severity was significantly more pronounced in NK ${ }^{\Delta c-F L I P}$ than in $\mathrm{NK}^{\mathrm{WT}}$ mice after the first 5-day period of DSS treatment (Fig. 5a). After termination of the first DSS treatment, NK ${ }^{\mathrm{WT}}$ mice had recovered completely until day 15 . This was not the case for $\mathrm{NK}^{\Delta \mathrm{c} \text {-FLIP }}$ mice. They failed to recover completely until day 19, when the second 5-day period of DSS administration was initiated (Fig. 5a). Importantly, NK ${ }^{\Delta c-F L I P}$ mice rapidly developed maximum disease scores comparable to those following the first phase of DSS treatment (Fig. 5a). NK ${ }^{\mathrm{WT}}$ mice showed elevated disease scores at day 25 , which were above those observed at the peak of the first treatment cycle but still significantly below those of $\mathrm{NK}^{\Delta \mathrm{c} \text {-FLIP }}$ mice (Fig. 5a).

Following the second DSS cycle, NK ${ }^{\mathrm{WT}}$ mice did not recover completely demonstrating the establishment of chronic colitis. Still, recovery was significantly less efficient in $\mathrm{NK}^{\Delta \mathrm{c} \text {-FLIP }}$ mice (Fig. 5a). After an additional phase of DSS treatment, disease scores in $\mathrm{NK}^{\mathrm{WT}}$ mice were slightly above those observed in the previous phase but still below those in $\mathrm{NK}^{\Delta \mathrm{c} \text {-FLIP }}$ mice (Fig. $5 \mathrm{a}$ ). Analysis of colon samples at day 42 revealed a significant decrease in colon length (Fig. 5b) and an increase in specific colon weight in $\mathrm{NK}^{\Delta \mathrm{c} \text {-FLIP }}$ mice (Fig. 5c). Furthermore, inflammation-related histopathological changes were more pronounced in the colon of $\mathrm{NK}^{\Delta \mathrm{c} \text {-FLIP }}$ mice (Fig. $5 \mathrm{~d}-\mathrm{f}$ ) correlating well with their increased disease severity (Fig. 5a).
The cytokine milieu has a major impact on the course of IBD ${ }^{34}$. We therefore determined cytokine production in supernatants of cultured colon samples isolated at days 3 and 10 after the initiation of DSS treatment. Except reduced levels of IFN- $\gamma$ and GM-CSF in $\mathrm{NK}^{\Delta \mathrm{c}-\mathrm{FLIP}}$ mice, levels of IL-22, IL-10, IL-12p70, TNF, IL-17A, IFN- $\beta$, IL- 6 and MCP- 1 did not differ significantly between mouse strains at day 3 (Fig. 5g; upper row). At day 10, IL-12p70, MCP-1, and GM-CSF levels were significantly lower in $\mathrm{NK}^{\Delta \mathrm{c}-F L I P}$ supernatants. On the contrary, all other cytokines were produced at comparable amounts (Fig. 5g; lower row). It is important to stress out that GM-CSF was the only cytokine that was reduced in $\mathrm{NK}^{\Delta \mathrm{c}-\mathrm{FLIP}}$ samples at both time points. Given that the relative importance of a particular cytokine correlates positively with the persistence of its production ${ }^{35}$, we hypothesized that GM-CSF is of particular importance for disease control in our model. In order to test whether the number of GM-CSF-producing ILC is altered in the inflamed colon of $\mathrm{NK}^{\Delta \mathrm{c}-\mathrm{FLIP}}$ mice, colonic lamina propria leukocytes (LPL) were analyzed by flow cytometry at day 5 of DSS treatment. As shown in Fig. 5h, numbers of GM-CSF ${ }^{+} \mathrm{NKp}^{+} 6^{+}$, but not $\mathrm{NKp}^{-} 6^{-}$, ILC were significantly reduced in $\mathrm{NK}^{\Delta \mathrm{c}-\mathrm{FLIP}}$ mice. GM-CSF promotes epithelial cell recovery after DSS treatment and GM-CSF deficiency is associated with disease aggravation $^{36}$. Hence, increased disease severity and impaired regeneration in $\mathrm{NK}^{\Delta \mathrm{c} \text {-FLIP }}$ mice (Fig. $5 \mathrm{a}-\mathrm{f}$ ) correlated with (i) the reduced production of GM-CSF in colon samples and (ii) lower numbers of $\mathrm{GM}^{-\mathrm{CSF}^{+}} \mathrm{NKp}^{+} 6^{+}$ILC in the colon of $\mathrm{NK}^{\Delta \mathrm{c}-\mathrm{FLIP}}$ mice (Fig. 5g, h). In summary, our data (Fig. 5a-h) provide evidence for a function of c-FLIP-dependent NKp46 ${ }^{+}$ILC1/3 in T/B-sufficient mice. These cells are crucial to limit intestinal inflammation, facilitate recovery and thereby prevent the early onset of chronic intestinal inflammation.

NKp46 ${ }^{+}$ILC counter inflammation-related commensal dysbiosis. Intestinal homeostasis is maintained by a multitude of interactions between immune cells, IEC and the commensal microbiota $^{6}$. Disruption of this complex network is frequently associated with aberrant immune responses, subsequent inflammation and microbial dysbiosis ${ }^{37,38}$. Particularly, we have shown that the severity of DSS colitis is influenced by specific interactions between microbial communities and host immune pathways with distinct changes in microbiota composition being sufficient for exacerbation of the disease ${ }^{39}$. We therefore asked next whether the presence or absence of $\mathrm{NKp} 46^{+}$ILC affects the relative abundance of pro- and/or anti-inflammatory bacteria in $\mathrm{NK}^{\mathrm{WT}}$ and $\mathrm{NK}^{\Delta \mathrm{c}-\mathrm{FLIP}}$ mice. For this purpose, feces samples were collected before induction of chronic DSS colitis (before DSS) and at the end of the observation period (after DSS). To minimize potential cage-specific variations in microbiota composition, $\mathrm{NK}^{\mathrm{WT}}$ and NK ${ }^{\Delta \mathrm{c}-\mathrm{FLIP}}$ mice littermates were, whenever possible, co-housed permanently. Feces samples were analyzed using $16 \mathrm{~S}$ rRNA gene sequencing of the V4 region ${ }^{40}$ and microbiota composition was compared between $\mathrm{NK}^{\mathrm{WT}}$ and $\mathrm{NK}^{\Delta \mathrm{c}-\mathrm{FLIP}}$ mice (Fig. 6a-c). Our analyses revealed a complex pattern of community structures in $\mathrm{NK}^{\mathrm{WT}}$ and $\mathrm{NK}^{\Delta \mathrm{c}-\mathrm{FLIP}}$ mice. The relative contribution of factors including "Genotype", "Cage", and "Time point" to variability within the microbiota demonstrated time point-dependent differences between both mouse lines (Fig. 6a; $\left.R^{2}=0.214, p<0.001\right)$ indicating that repeated colitis induction had a lasting impact on the microbiome composition. Notably, genotype-dependent differences in microbiome composition were not visible before induction of DSS colitis (Fig. 6a, b; ADONIS values). Thus, NKp46 ${ }^{+}$ILC do not have a major impact on the composition of the commensal microbiota under steady-state conditions. Under inflammatory conditions, however, the presence or absence of $\mathrm{NKp}_{4} 6^{+}$ILC in $\mathrm{NK}^{\mathrm{WT}}$ or $\mathrm{NK}^{\Delta \mathrm{c} \text {-FLIP }}$ mice, 
a

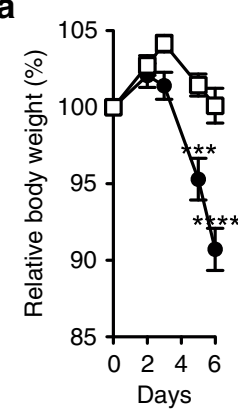

g

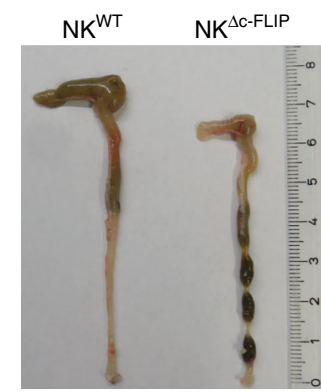

b
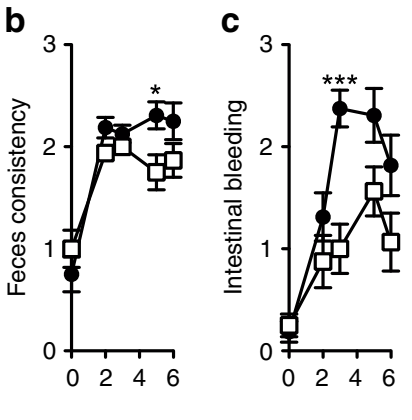
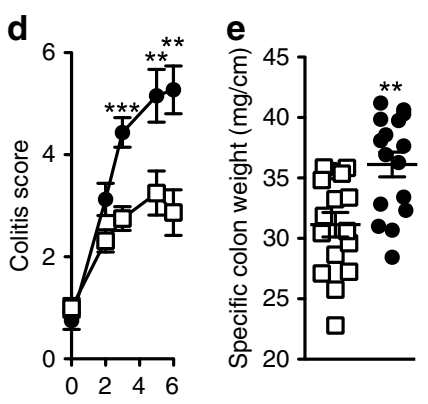

f

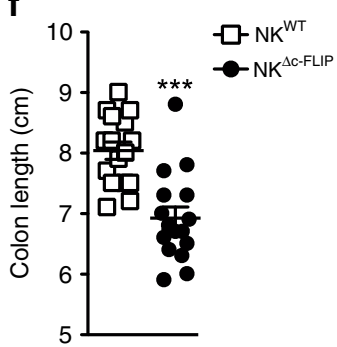

i
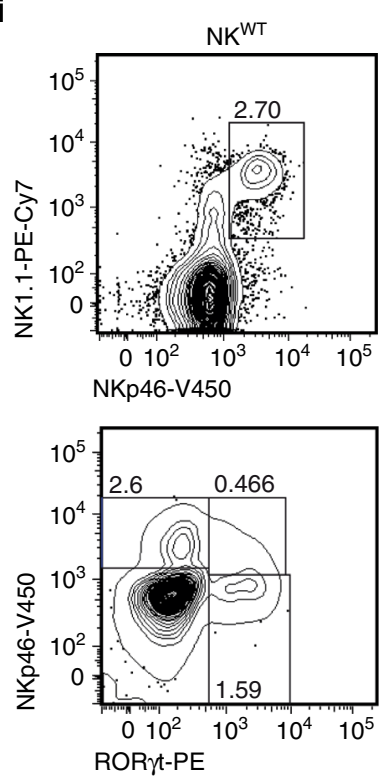

I

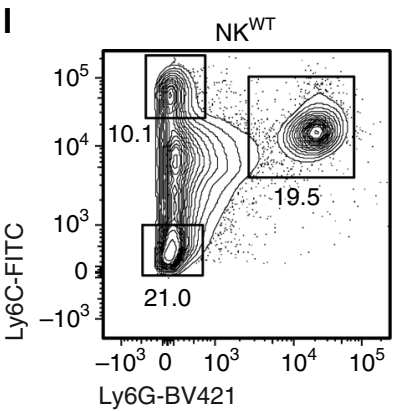

$\mathbf{h}$

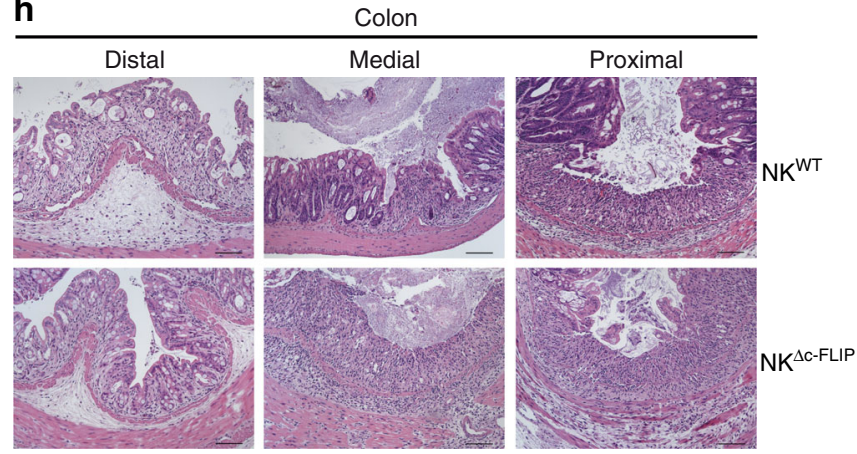

$\mathrm{NK}^{\Delta \mathrm{c}-\mathrm{FLIP}}$

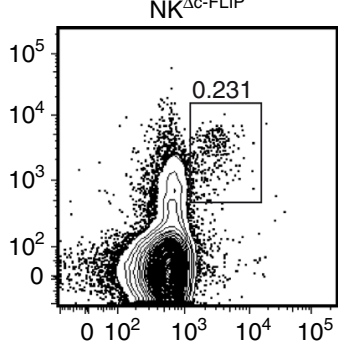

j

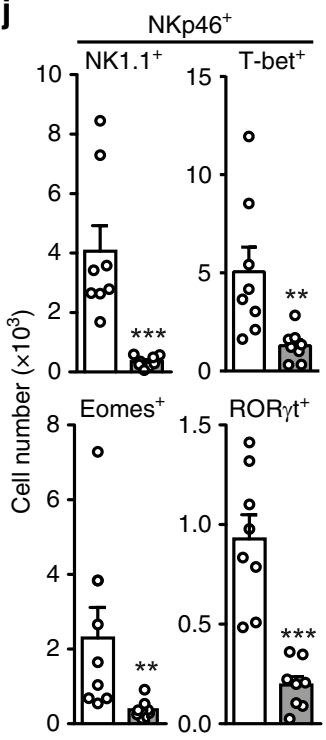

k $\frac{\mathrm{NKp}^{-} 6^{-}}{\mathrm{ROR} \gamma \mathrm{t}^{+}}$

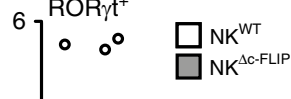

$4-\frac{1}{2}$

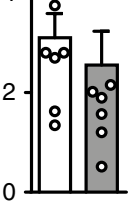

GATA-3
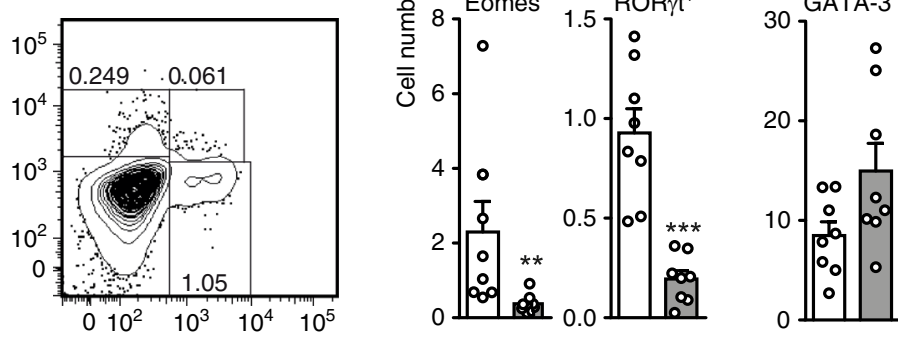

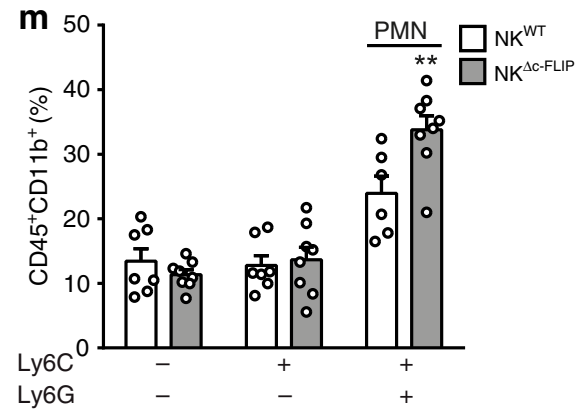

respectively, is associated with genotype-specific changes in the microbiota (Fig. 6c; $R^{2}=0.123, p<0.01$ ).

Additionally, we compared the bacterial taxa in the commensal microbiota of $\mathrm{NK}^{\mathrm{WT}}$ and $\mathrm{NK}^{\Delta \mathrm{c}-\mathrm{FLIP}}$ mice. In line with Fig. $6 \mathrm{a}-\mathrm{c}$, the composition of the commensal microbiota was very similar prior to the induction of colitis (Fig. 6d). In contrast, chronic DSS colitis induced overt changes in microbiome composition in both mouse strains and distinct changes between them (Fig. 6e).

We used the linear discriminant analysis (LDA) effect size (LEfSe) method considering only operational taxonomic units 
Fig. 4 c-FLIP-dependent NKp46 ${ }^{+}$ILC protect mice from acute intestinal inflammation. a-m NKWT and NK ${ }^{\Delta c-F L I P}$ mice were treated with DSS for 5 days. $\mathbf{a}$ Relative body weight, $\mathbf{b}$ feces consistency and $\mathbf{c}$ the degree of intestinal bleeding were measured on a daily basis to calculate $\mathbf{d}$ the overall colitis score. At day 7, e the specific weight and $\mathbf{f}, \mathbf{g}$ the length of the colon were determined. $\mathbf{g}, \mathbf{h}$ Shown are representative photographs of $\mathbf{g}$ colon and cecum (scale unit $=\mathrm{cm}$ ) as well as $\mathbf{h} \mathrm{H \& E}$-stained tissue sections from NKWT and NK $\Delta \mathrm{c}$-FLIP mice $(n=6 /$ group) at day 7 (scale bars $=100 \mu \mathrm{m})$. $\mathbf{i}-\mathbf{m}$ At day 7 , colonic lamina propria leukocytes were analyzed by flow cytometry. i-k After gating on Lin ${ }^{-}$CD45 $5^{+}$cells, the different subsets of NKp46+ (ILC: NK1.1+; ILC1: T-bet $^{+}$, cNK: Eomes ${ }^{+}$; ILC3: RORyt ${ }^{+}$) and NKp46- ILC (ILC3: RORyt ${ }^{+}$; ILC2: GATA3 ${ }^{+}$) were analyzed in eight mice per group. I, $\mathbf{m}$ Colon samples from two mice were pooled and Ly6C+/-Ly6G- monocyctes and Ly6C+Ly6G+ neutrophils $(P M N)$ were analyzed by flow cytometry $(6-8$ samples per group). i, I Representative contour plots are shown. Numbers indicate percentages. a-f, $\mathbf{i}-\mathbf{m}$ Data were pooled from two independent experiments with a total of 15-16 mice per group. Data show means + SEM; ${ }^{\star} p \leq 0.05 ;{ }^{\star \star} p \leq 0.005 ;{ }^{\star \star \star} p \leq 0.001 ;{ }^{\star \star \star \star} p \leq 0.0001$ (two-tailed Mann-Whitney $U$ test). Source data are provided as source data file.

(OTUs) with the Kruskal-Wallis test $<0.05$ and LDA scores $>3.0$ to identify statistically significant differences ${ }^{41}$ between diseased $\mathrm{NK}^{\mathrm{WT}}$ and $\mathrm{NK}^{\Delta \mathrm{c}-\mathrm{FLIP}}$ mice (Fig. 6f). In NK ${ }^{\mathrm{WT}}$ mice the genera Prevotella (OTU 8), Muribaculum (OTU 5; within the Bacteriodales S24-7), Alistipes (OTU 33; within the family Rikenellaceae) and two undefined OTUs (OTU 94 and OTU 76; within the family Ruminococcaceae) relatively expanded in the course of DSS colitis (Fig. 6f). In feces of $\mathrm{NK}^{\Delta \mathrm{c} \text {-FLIP }}$ mice the frequencies of bacteria belonging to the genera Turicimonas (OTU 75; within the Alcaligenaceae), Turicibacter (OTU 2; within the Erysipelotrichaceae), Bacteroides (OTU 12; within Bacteroidaceae) and a bacterium belonging to an ambiguous taxon (OTU 61; within the Coriobacteriaceae) were significantly increased. Elevated levels of Turicibacter and Bacteroides correlate positively with inflammation and tumor development in mice ${ }^{42}$. Moreover, expansion of Alcaligenaceae is frequently observed in Crohn's disease patients and drives systemic inflammation in mice ${ }^{43}$. Hence, the lack of $\mathrm{NKp} 46^{+}$ILC in NK ${ }^{\Delta c-F L I P}$ mice is associated with increased disease severity (Fig. 5a-f), altered cytokine expression (Fig. 5g, h) and the subsequent expansion of potentially pathogenic bacteria (Fig. 6a-f).

IL-7R-dependent NKp46 ${ }^{+}$ILC3 do not affect acute colitis. In DSS-treated mice, NKp46 ${ }^{+}$ILC3 are an important source of tissueprotective IL-22 and their deletion in T/B-deficient $\mathrm{RAG}^{-1-}$ mice is associated with increased disease severity ${ }^{8}$. We therefore hypothesized that the lack of NKp46 ${ }^{+}$ILC3 was responsible for disease aggravation in $\mathrm{NK}^{\Delta \mathrm{c}-\mathrm{FLIP}}$ mice (Figs. $4 \mathrm{a}-\mathrm{h}$ and $5 \mathrm{a}-\mathrm{f}$ ). In order to eliminate $\mathrm{NKp} 46^{+}$ILC3 from T/B-competent mice, we exploited the strict IL-7R-dependence of NKp46 $6^{+} \mathrm{ROR} \gamma \mathrm{t}^{+}$ILC3 (Fig. 3l). For this purpose, conditional IL-7R (IL-7R $\left.\mathrm{R}^{\mathrm{f} / \mathrm{fl}}\right)$ knockout mice were crossed to NKp46 ${ }^{\mathrm{iCre}}$-transgenic mice to generate $\mathrm{NK}^{\Delta \mathrm{IL}-7 \mathrm{R}}$ mice. As compared to $\mathrm{NK}^{\mathrm{WT}}$ mice, SI-derived helper-like $\mathrm{NKp} 46^{+} \mathrm{CD} 90^{+}$ILC from NK ${ }^{\Delta \mathrm{IL}-7 \mathrm{R}}$ mice hardly expressed any IL7Ra (CD127) while non-targeted NKp46-CD90 ${ }^{+}$ILC still expressed it at normal levels. As expected, $\mathrm{NKp} 46^{+} \mathrm{CD} 90^{-} \mathrm{cNK}$ expressed least IL-7R in both mouse strains ${ }^{32}$ (Fig. 7a). Next, we determined the composition of the ILC pool in the SI of NK ${ }^{\mathrm{WT}}$ and $\mathrm{NK}^{\Delta \mathrm{IL}-7 \mathrm{R}}$ mice. $\mathrm{NK}^{\Delta \mathrm{IL}-7 \mathrm{R}}$ mice were nearly completely devoid of NKp46 ${ }^{+} \mathrm{ROR}_{\mathrm{t}} \mathrm{t}^{+}$ILC3 (Fig. 7b, c), while numbers of NKp46 ${ }^{+}$Tbet $^{+}$ILC1 (Fig. 7c), NKp46 ${ }^{+}$Eomes $^{+}$cNK (Fig. 7b, c), and all NKp46- ILC subsets (Fig. 7c) appeared normal compared to $\mathrm{NK}^{\mathrm{WT}}$ mice.

Next, we tested whether the lack of $\mathrm{NKp} 46^{+} \mathrm{ROR} \gamma \mathrm{t}^{+}$ILC3 affects the outcome of acute DSS colitis. For this purpose, NK ${ }^{\mathrm{WT}}$ and NK $\mathrm{K}^{\Delta \mathrm{IL}-7 \mathrm{R}}$ mice were treated with DSS for 5 days and disease parameters were determined. As shown in Fig. 7d, relative body weight did not differ between both mouse strains. Altogether, our results demonstrate that the lack of NKp $46^{+}{ }^{R O R} \gamma t^{+}$ILC3 does not affect the course of DSS-induced colitis.

cNK cells ameliorate acute intestinal inflammation. Since NKp46 ${ }^{+}$ILC3 did not affect the course of DSS-induced colitis
(Fig. 7d), we hypothesized that NKp46 ${ }^{+}$ILC1 deficiency accounted for disease aggravation in NK ${ }^{\Delta c-F L I P}$ mice (Figs. $4 a-h$ and $5 \mathrm{a}-\mathrm{f})$. This assumption was supported by the fact that the mild course of disease in $\mathrm{NK}^{\mathrm{WT}}$ mice correlated with the accumulation of c-FLIP-dependent $\mathrm{Ly}_{4} 9 \mathrm{C}^{+} \mathrm{cNK}$ (Supplementary Fig. 3). In order to elucidate whether $\mathrm{cNK}$ are involved in disease modulation, B6 mice were treated with cNK-depleting antiAsialo-GM1 (aAsialo) or control antibody. As shown in Supplementary Fig. 4A, aAsialo-treated mice suffered more from DSS-induced colitis than control animals. Since the efficacy of cNK depletion may vary between target tissues, we analyzed the frequencies and absolute numbers of colonic ILC. Anti-Asialotreated mice contained significantly fewer NKp $46^{+} \mathrm{NK} 1.1^{+}$ILC in the inflamed colon (Supplementary Fig. 4B, F, I). This reduction was mainly due to the depletion of $\mathrm{NKp} 46^{+} \mathrm{NK} 1.1$ ${ }^{+}$Eomes ${ }^{+} \mathrm{cNK}$ (Supplementary Fig. 4C, G, J) and correlated with elevated frequencies of neutrophils in peripheral blood (Supplementary Fig. 4E), similar to what we had observed in the inflamed colon of NK ${ }^{\Delta c-F L I P}$ mice (Fig. 41 and $\mathrm{m}$ ). On the contrary, frequencies of NKp46 ${ }^{+}$Eomes $^{-}$ILC1 (Supplementary Fig. 4C) and NKp46 ${ }^{+/-}$ROR $\gamma \mathrm{t}^{+}$ILC3 (Supplementary Fig. 4D, H) remained largely unaffected by aAsialo treatment, whereas absolute numbers of the latter were significantly reduced (Supplementary Fig. 4K). Hence, antibody-mediated side effects on other ILC subsets could not be formally excluded.

As a result of NKp46-specific Eomes inactivation, cNK development is strongly impaired while other ILC remain largely unaffected ${ }^{4-46}$. We therefore generated cNK-deficient $\mathrm{NK}^{\Delta \mathrm{E} \text { Emes }}$ $\left(\mathrm{NKp} 46^{\mathrm{iCre}} \times\right.$ Eomes $\left.^{\mathrm{fl} / \mathrm{fl}}\right)$ mice to further validate the antiinflammatory function of $\mathrm{cNK}$. $\mathrm{NK}^{\Delta \mathrm{E} \text { Emes }}$ mice and control animals were treated with DSS for 5 days. Similar to NK ${ }^{\Delta c \text {-FLIP }}$ (Fig. 4a-d) and aAsialo-treated B6 mice (Supplementary Fig. 4A), disease severity was significantly increased in $\mathrm{NK}^{\Delta \mathrm{Eomes}}$ mice as compared to NK ${ }^{\mathrm{WT}}$ controls (Fig. 8a-d). In accordance with a more pronounced inflammatory response, colon weight of $\mathrm{NK}^{\Delta E}$ Eomes mice was increased (Fig. 8e) while its length was decreased (Fig. 8f, g). Importantly, we confirmed the selective loss of Eomes ${ }^{+} \mathrm{cNK}$, but not helper-like ILC1, in the inflamed colon of $\mathrm{NK}^{\Delta \mathrm{Eomes}}$ mice (Fig. 8h, i). This correlated with the accumulation of neutrophils (Fig. 8j, k) similar to what we had observed for $\mathrm{NK}^{\Delta \mathrm{c}-\mathrm{FLIP}}$ mice (Fig. 41, m). Thus, cNK depletion, either by aAsialo treatment (Supplementary Fig. 4) or NKp46specific Eomes inactivation (Fig. 8), is sufficient to aggravate disease. Hence, our results strongly suggest that $\mathrm{cNK}$ act as immune modulators in the inflamed colon with antiinflammatory properties superior to all other $\mathrm{NKp} 46^{+}$ILC.

\section{Discussion}

Immune cells are equipped with a multitude of cytokine receptors allowing them to sense changes in their environment and adapt activation as well as survival thresholds accordingly 13,47 . How cytokine signals are translated into ILC-specific developmental/ survival programs is largely unknown. IL-15 is an environmental 
a

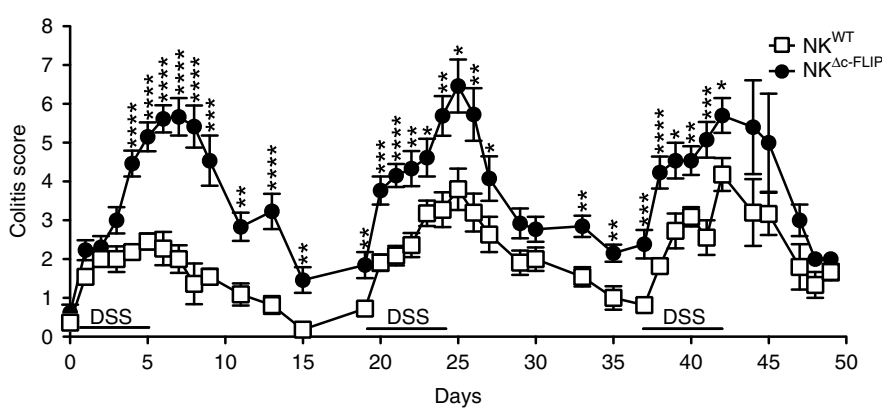

d
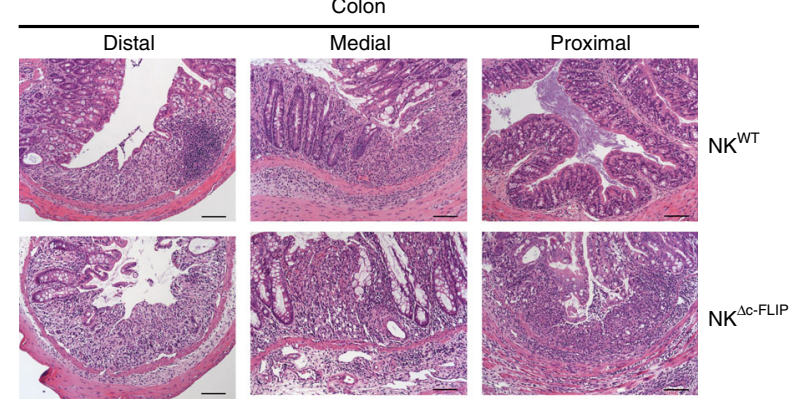
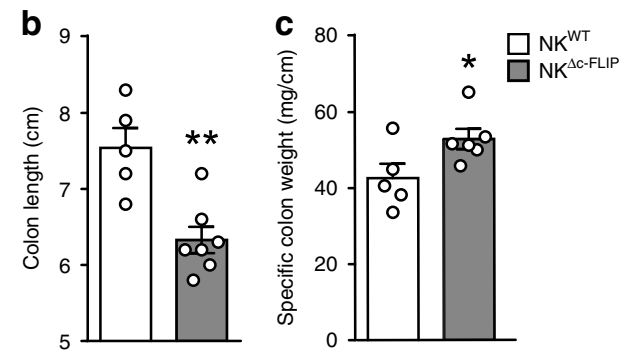

e

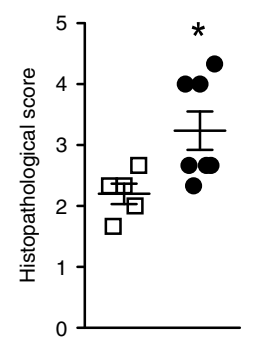

f

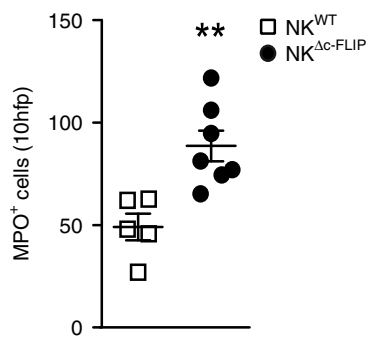

g
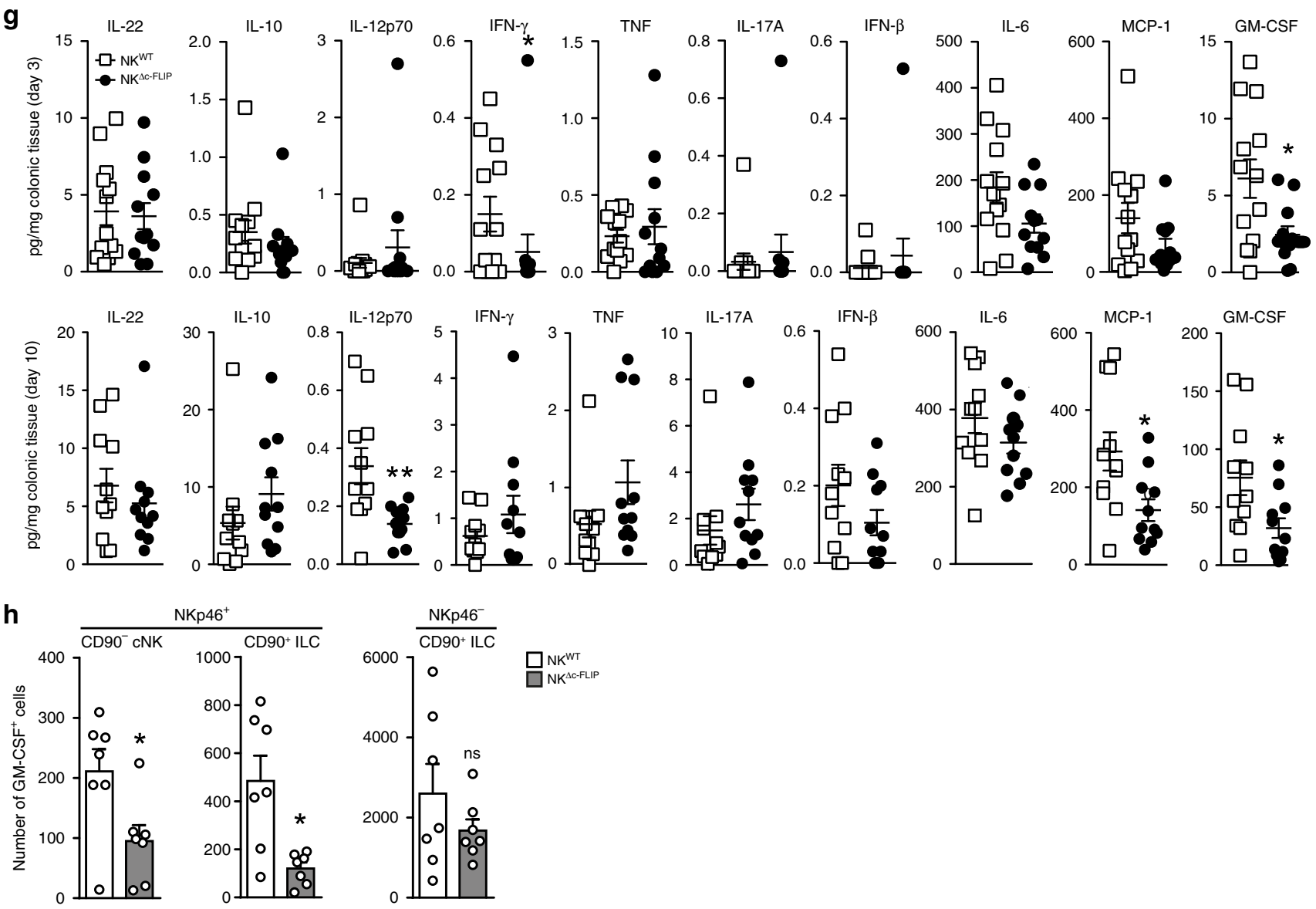

factor that is indispensable for ILC1/cNK development ${ }^{25,26}$. Previous studies demonstrated that IL-15 withdrawal impairs cNK metabolism ${ }^{48}$ and activates the intrinsic apoptosis pathway ${ }^{15}$. In the absence of IL-15 cNK fail to downregulate the proapoptotic molecule Bim. At the same time, the induction of the anti-apoptotic Mcl-1 is impaired and IL-15-deprived cNK undergo apoptosis ${ }^{15}$.
Here, we provide evidence for an additional mode of ILCspecific, non-redundant IL-15 action. We identify c-FLIP as a target of STAT5-dependent IL-15 signaling. c-FLIP is a master regulator of the extrinsic apoptosis pathway ${ }^{20}$ and protects immune and non-immune cells from caspase 8-dependent apoptosis ${ }^{21,22}$. Usually, this type of apoptosis is triggered by DLs such as TNF or TRAIL, which are produced at high levels by 
Fig. 5 The lack of c-FLIP-dependent NKp46+ ILC is associated with the early onset of chronic intestinal inflammation. a-h NKWT and NK ${ }^{\Delta c-F L I P ~}$ littermates were treated with DSS for 5 days followed by a 14-day recovery phase on normal drinking water. This treatment was repeated twice. a Shown are representative results (mean colitis score \pm SEM) of one out of two independent experiments with 11-13 mice per group. b-f At day 42, b colon length and $\mathbf{c}$ specific colon weight were determined, $\mathbf{d}$-f tissue samples from distal, medial, and proximal colon were collected and $\mathbf{d}$, e stained with H\&E (scale bars $=100 \mu \mathrm{m}$ ) to determine $\mathbf{e}$ histopathological scores (HPS). $\mathbf{f}$ For each colon segment, myeloperoxidase (MPO) ${ }^{+}$cells were enumerated in 10 high power fields (magnification $\times 400$ ). e, $\mathbf{f}$ Each symbol represents mean values for individual mice after pooling results from the three colon segments. $\mathbf{b}$, $\mathbf{c}$, e, f Data show mean $+/ \pm$ SEM for the respective experimental groups. b-f 5-7 mice were analyzed. $\mathbf{g}$ At experimental days 3 (upper row) and 10 (lower row), colon samples were isolated and incubated for $24 \mathrm{~h}$. Cytokine levels were determined in culture supernatants and normalized to tissue mass ( $n=11-13 /$ group). h At day 5, frequencies of GM-CSF-producing cells isolated from the colonic lamina propria were determined by flow cytometry. After gating on Lin- CD45+ cells, GM-CSF production was analyzed for NKp46+CD90- cNK as well as NKp46 ${ }^{+/-}$CD90 + helper-like ILC. Pooled results $($ mean + SEM) from four independent experiments with a total of seven colon samples (pooled from 2 to 3 mice) per group are shown. Statistical significances were determined using $\mathbf{a}, \mathbf{e}, \mathbf{f}, \mathbf{g}, \mathbf{h}$ two-tailed Mann-Whitney $U$ and $\mathbf{b}, \mathbf{c}$ two-tailed unpaired Student's $t$ test $\left({ }^{\star} p \leq 0.05 ;{ }^{* \star} p \leq 0.005\right.$; ${ }^{\star \star \star} p \leq 0.001 ;{ }^{\star \star \star \star} p \leq 0.0001 ;$ ns $=$ not significant). $\mathbf{a}-\mathbf{c}$ and $\mathbf{e}-\mathbf{h}$ Source data are provided as source data file.

mature ILC1 ${ }^{29}$. To prevent their DL-induced premature death in the course of an immune response c-FLIP is required ${ }^{30}$. Our results demonstrate that immature ILC already require c-FLIP in the very early phase of their development. This appears to be due to the fact that developing ILC up-regulate effector genes such as Ifng and Tnf already at the SP stage. This is paralleled by DR upregulation, particularly of TNF-R1, thus rendering BM ILC sensitive to TNF-induced apoptosis. Consequently, only c-FLIPcompetent ILC precursors developed into DP ILC in vitro. Importantly, the blockade of TNF partially restored the generation of c-FLIP-deficient DP ILC. Whether TNF production by developing ILC is a cell autonomous process or whether it is influenced by environmental factors remains to be shown.

T/B-deficient mice lacking NKp46 ${ }^{+}$ILC3 succumb to $C$. rodentium infection. On the contrary, their T/B-competent counterparts control infection ${ }^{9,10}$. This demonstrates that adaptive immune cells and $\mathrm{NKp} 6^{+}$ILC have redundant functions ${ }^{9,10}$, a conclusion that is supported by human data ${ }^{11}$. However, NKp46 ${ }^{+}$ILC3 are indispensable for the maintenance of cecal homeostasis 9 . Hence, the relative contribution of NKp $46^{+}$ILC to the modulation of immune responses appears to vary in a context-dependent fashion. This is further exemplified by apparently opposing results obtained in mouse models of intestinal inflammation. While NKp46 ${ }^{+}$ILC3 protect T/B-deficient mice from DSS-induced colitis ${ }^{8}$, they promote aCD40induced colitis in T-deficient mice ${ }^{10}$. Whether and how NKp46 ILC affect the severity of DSS-induced colitis in T/B-competent mice had not been studied in detail before. To address this issue, we used ILC1/3-deficient, T/B-competent $\mathrm{NK}^{\Delta \mathrm{c} \text {-FLIP }}$ mice. Our data clearly demonstrate that NKp46 ${ }^{+}$ILC are indispensable for disease control. Neither T or B lymphocytes nor NKp46- ILC were able to compensate for the lack of NKp46 ${ }^{+}$ILC in $\mathrm{NK}^{\Delta \mathrm{c}-}$ FLIP mice. Importantly, with the help of NK $\mathrm{NK}^{\Delta \mathrm{L}-7 \mathrm{R}}$ mice, we could exclude NKp46 ${ }^{+}$ILC3 as major regulators of acute DSS-induced colitis emphasizing the importance of NKp46 ${ }^{+}$ILC1. In DSStreated $\mathrm{NK}^{\Delta \mathrm{c} \text {-FLIP }}$ mice, ILC-deficiency correlated with increased disease scores, altered cytokine profiles and the accumulation of neutrophils in the inflamed colon. Our data suggest that this neutrophil-associated effect was due to the lack of cNK, which can limit the recruitment and pro-inflammatory function of neutrophils ${ }^{49}$. This anti-inflammatory function of $\mathrm{cNK}$ is NKG2A-dependent as shown by the fact that anti-NKG2A antibodies block cNK-neutrophil interactions in vitro and exacerbate DSS-induced colitis in vivo. Based on these observations, a dominant regulatory role of $\mathrm{cNK}$ in DSS-induced colitis was postulated ${ }^{49}$. However, NKG2A is not only expressed by cNK but also by, e.g. $\mathrm{ILC1}^{26}$ and $\mathrm{CD} 8^{+} \mathrm{T}$ cells ${ }^{50}$. Hence disease exacerbation in response to anti-NKG2A treatment ${ }^{49}$ may involve multiple $\mathrm{NKG}_{2} \mathrm{~A}^{+}$immune cell types. However, as we have shown here, (i) the mild course of disease in $\mathrm{NK}^{\mathrm{WT}}$ mice correlated with the accumulation c-FLIP-dependent $\mathrm{Ly} 49 \mathrm{C}^{+}$ cNK, (ii) aAsialo-GM-mediated cNK depletion aggravated disease in B6 mice and, above of all, cNK-deficient $\mathrm{NK}^{\Delta \text { Eomes }}$ mice were by far more sensitive to DSS-induced colitis as compared to controls. Of note, disease aggravation was comparable for cNKdeficient $\mathrm{NK}^{\Delta \mathrm{E} \text { Emes }}$ and $\mathrm{NK}^{\Delta \mathrm{C} \text {-FLIP }}$ mice lacking all NKp $46^{+}$ILC. Hence, our findings support the view that $\mathrm{cNK}$ have a dominant anti-inflammatory function in DSS-induced colitis, which results, at least partially, from the restriction of neutrophil infiltration and function in the inflamed colon $^{51}$. However, it is important to emphasize that the cell surface molecules used to define neutrophils in our experimental system are used to define myeloidderived suppressor cells (MDSCs) in others ${ }^{52}$. In addition to their nearly identical cell surface phenotype, MDSCs and neutrophils share functional features as well. For example, and contrary to their well-known anti-inflammatory functions in tumor models ${ }^{53}$, MDSCs were shown to promote DSS-induced colitis ${ }^{54}$ similar to neutrophils ${ }^{49}$. Hence, our experimental approach does not allow us to define the relative contribution(s) of MDSCs and neutrophils to disease progression. Based on the complex intercellular interactions driving colitis ${ }^{55}$ we also cannot exclude that $\mathrm{cNK}$ deficiency promotes pro-inflammatory functions of other cell types.

$\mathrm{NK}^{\Delta \mathrm{c}-\mathrm{FLIP}}$ mice developed maximum disease scores after only a single phase of DSS administration. Furthermore, they failed to recover completely after the first DSS cycle and showed maximum disease scores after each additional DSS phase. This early establishment of chronic disease in NK ${ }^{\Delta \mathrm{c} \text {-FLIP }}$ mice correlated with the prolonged reduction of tissue-protective GM-CSF and lower numbers of GM-CSF ${ }^{+} \mathrm{NKp}^{+} 6^{+}$ILC including cNK. Hence, the protective effect of cNK may not only rely on the suppression of neutrophil effector functions but also on the production of tissueprotective GM-CSF. It is important to stress that no other immune cell type, including $\mathrm{NKp} 46^{+} \mathrm{ILCl} / 3$, is able to compensate for the early protective and regenerative effects of $\mathrm{NKp} 46^{+} \mathrm{cNK}$. This may, at least partially, rely on the disease-related control of the commensal microbiota. Of note, the lack of NKp46 ${ }^{+}$ILC in NK ${ }^{\Delta c-}$ FLIP mice did not have a significant impact on the composition of the commensal microbiota prior to DSS-induced colitis. This argues against a direct impact of NKp46 ${ }^{+}$ILC on the establishment of the microbiota under homeostatic conditions in T/Bcompetent mice. Nevertheless, after establishment of chronic colitis the composition of the commensal microbiota changed in a NKp46 ${ }^{+}$ILC-dependent fashion. For example, Coriobacteriaceae, Alcalignaceae, Erysipelotrichaceae, and Bacteroidaceae were more abundant in NK ${ }^{\Delta \mathrm{c}-\mathrm{FLIP}}$ mice, while Rikenellaceae, Bacteriodales S24-7, Prevotellaceae, and Ruminococcaceae were enriched in $\mathrm{NK}^{\mathrm{WT}}$ mice. Commensal dysbiosis is frequently observed in different disease models and the altered abundance of certain bacteria has disease-modulating effects ${ }^{37,38}$. For example, the 
a

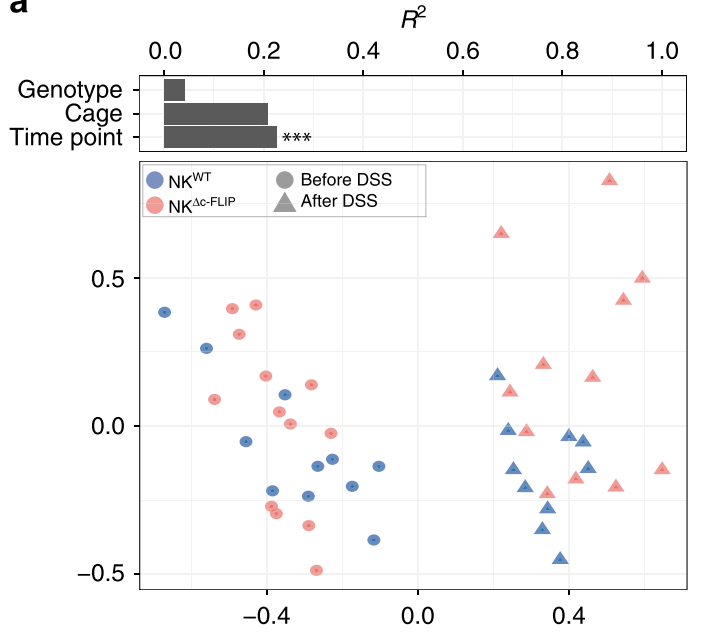

b

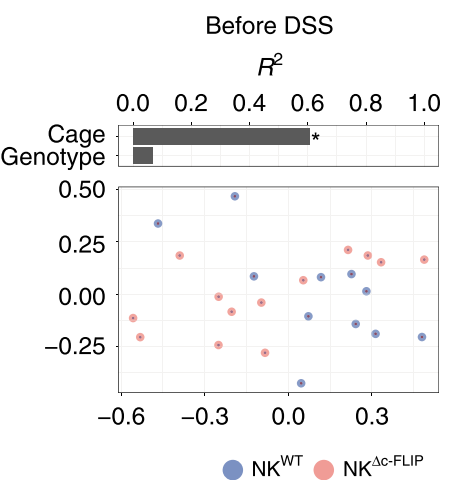

C

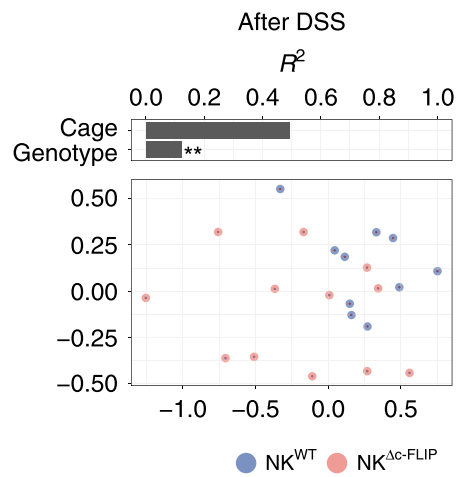

d
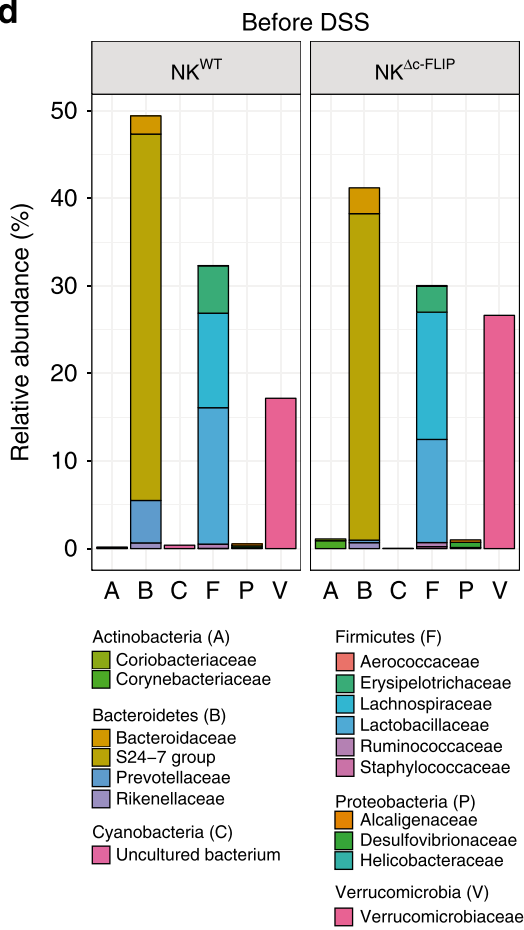

e
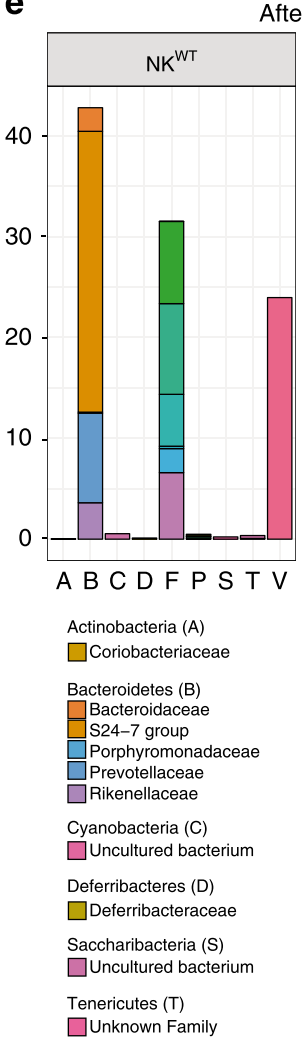

After DSS

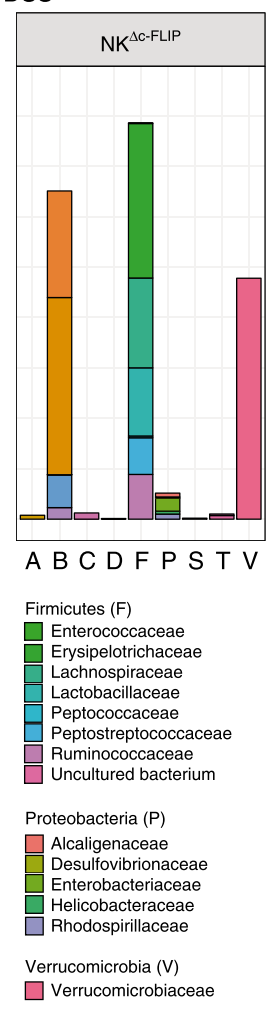

$\mathbf{f}$

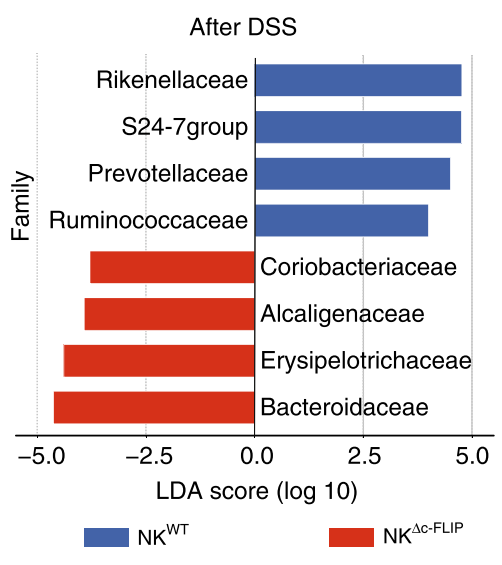

Fig. 6 The lack of c-FLIP-dependent NKp46+ ILC is associated with disease-related alterations in microbiome composition. a-f Feces samples of NKWT and NK ${ }^{\Delta c}$-FLIP littermates (Fig. 5) were collected before DSS administration (before DSS) and at the end of the observation period (after DSS, d49). Whenever possible, mice shared cages from birth on and throughout the experiments. Analyzed samples ( $n=10-13 /$ group and time point) had a minimum sequencing depth of 1000 reads and a mean sequencing depth of 19,298.3 \pm 7781.349 reads (mean \pm SD). a-c Non-metric multidimensional scaling (NMDS) ordination analysis of fecal microbiota composition was performed using Bray-Curtis distances grouped by a genotype and treatment or b, c genotype $\mathbf{b}$ before and $\mathbf{c}$ after DSS-induced colitis. Individual effect size of tested covariates is indicated. a-c To calculate the variance explained by individual factors such as genotype, cage effect, and treatment a permutational multivariate analysis of variance (ADONIS) was used. ${ }^{*} p<0.05$; ${ }^{* \star} p<0.01$; ${ }^{\star \star \star} p<0.001$. A significant effect was dedicated when $p<0.05$ and $R^{2}>0.10$ (equivalent to $10 \%$ of explained variance). d, e Relative abundance of the average microbiome composition $\mathbf{d}$ before and $\mathbf{e}$ after DSS administration was determined on the family level. Phylum and families are indicated. f Statistically significant differences on family levels in fecal microbiota composition between NKWT and NK ${ }^{\Delta c-F L I P}$ mice. Data were analyzed using linear discriminant analysis (LDA) effect size (LEfSe) method (Kruskal-Wallis test with $p<0.05$ and LDA scores $>3.0$ ). Data are displayed as bar plot ranked according to their effect size and associating them to the genotype of the mice. a-f Source data are provided as source data file.

overabundance of Bacteroides has been associated with increased rates of inflammation and tumor development ${ }^{42}$. Moreover, the expansion of bacteria from the family Alcaligenaceae drives inflammation in ILC-depleted RAG1 ${ }^{-1-}$ mice ${ }^{43}$. On the contrary, the enhanced relative abundance of Prevotella in diseased $\mathrm{NK}^{\mathrm{WT}}$ mice may have beneficial effects, since it correlates inversely with inflammation in a mouse model of inflammation-induced carcinogenesis $^{42}$. Altogether, these results demonstrate that the 

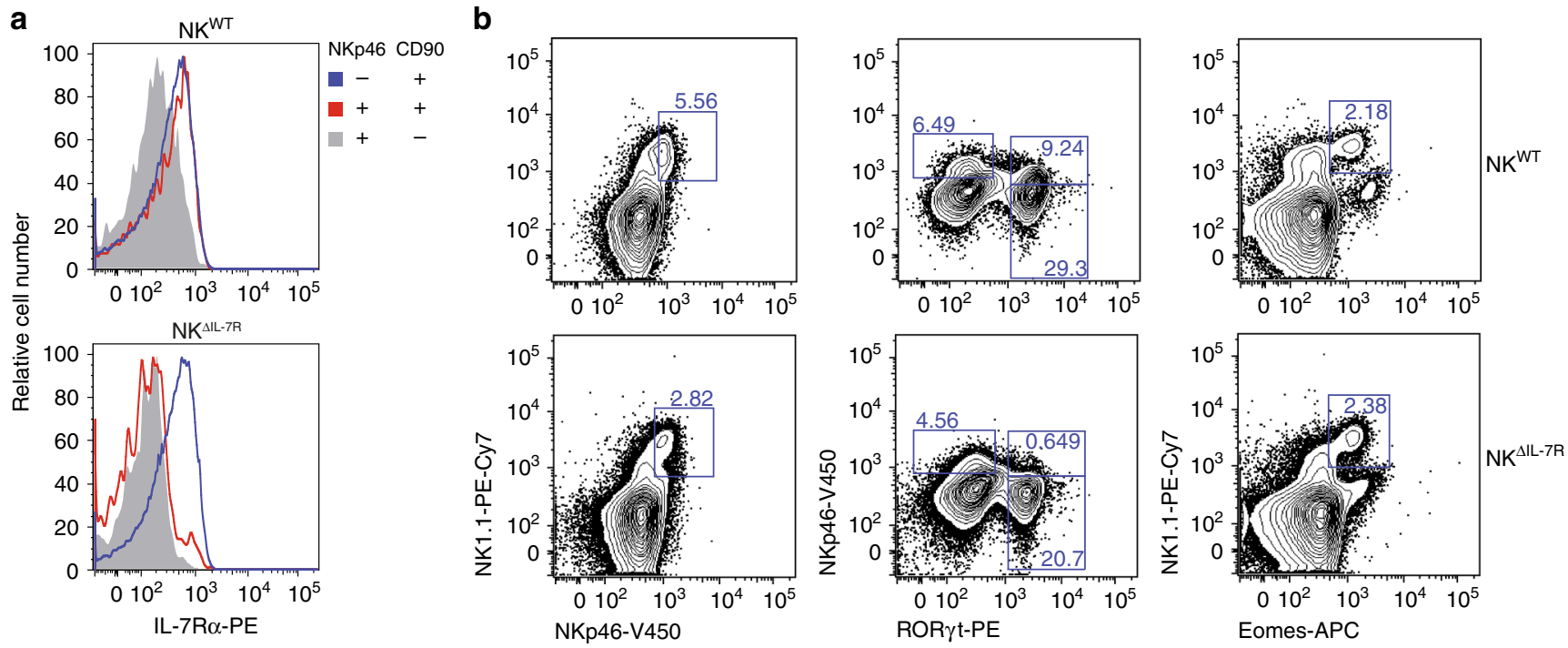

C
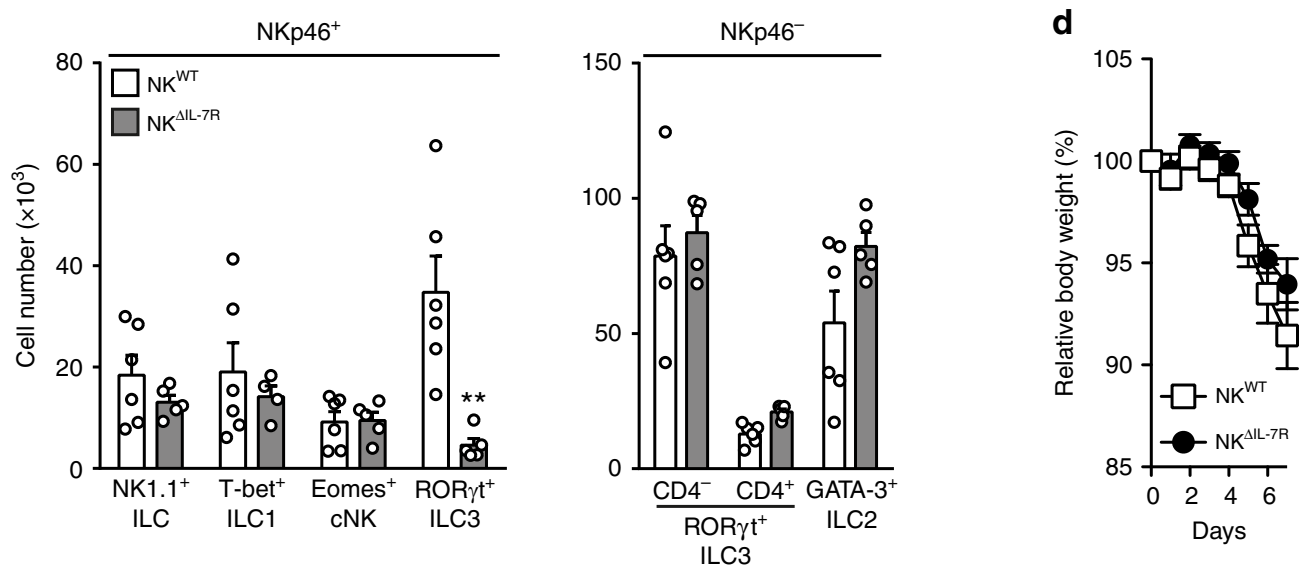

Fig. 7 IL-7R-dependent ILC3 do not affect acute colitis. a-c Small intestinal lamina propria leukocytes were isolated from NKWT and NK ${ }^{\Delta I L-7 R}$ mice. Cells were analyzed by flow cytometry as described in Fig. 3. a Overlays show relative fluorescence intensities of IL-7R $\alpha$ (CD127) for the indicated ILC. Data are representative for four mice per genotype. b Shown are representative contour plots and c pooled results (means + SEM) from two independent experiments with 5-6 mice per group. Four to six samples were analyzed. d To induce acute colitis, NKWT and NK ${ }^{\Delta I L-7 R}$ mice were treated with DSS for 5 days as described in Fig. 4. Relative body weights were determined on a daily basis. Pooled results (means \pm SEM) from two independent experiments with 17-18 mice per group are shown. $\mathbf{c}$, d Source data are provided as source data file; ${ }^{\star} p \leq 0.05 ;{ }^{\star \star} p \leq 0.005 ;{ }^{\star \star \star} p \leq 0.001 ;{ }^{\star \star \star \star} p \leq 0.0001$ (two-tailed Mann-Whitney $U$ test).

expansion of disease-promoting microbes, such as Proteobacteria, i.e. Alcaligenaceae, occurs selectively in DSS-treated $\mathrm{NK}^{\Delta c \text {-FLIP }}$ mice. This indicates that c-FLIP-dependent NKp46 ${ }^{+}$ILC modulate the composition of the commensal microbiota under inflammatory conditions but not prior to disease. Whether alterations of the commensal microflora are a cause or a result of inflammation remains an important question for the future.

In summary, we identify the anti-apoptotic molecule c-FLIP as a target of cytokine-induced STAT5 activation, which is indispensable for the development of IL-15- and IL-7-dependent NKp46 ${ }^{+}$ILC1 and ILC3, respectively. Furthermore, we provide evidence that $\mathrm{cNK}$, but not ILC1/3, restrict the degree of intestinal inflammation correlating with specific alterations in the commensal microbiota. Hence, c-FLIP-dependent $\mathrm{NKp} 46^{+} \mathrm{cNK}$ protect $\mathrm{T} / \mathrm{B}$-sufficient mice from intestinal inflammation, a function that cannot be replaced by any other immune cell.

\section{Methods}

Mice. NKp46 ${ }^{\text {iCre }} 19$, c-FLIPf/fl 23, STAT5 $5^{\mathrm{fl} / \mathrm{fl}} 56$ (provided by L. Hennighausen), IL-15 ${ }^{-1-25}$, IFN- $\gamma$ reporter mice (Great) ${ }^{57}$, RAG1 ${ }^{-1-58}$, IL-7R $\mathrm{R}^{-1-59}$, and $\mathrm{RAG1}^{-/-} \times \mathrm{IL}^{-} 7 \mathrm{R}^{-/-}$were maintained under specific pathogen-free conditions at the central animal facility of the Medical Faculty of the Otto-von-GuerickeUniversity Magdeburg. IL-7R $\mathrm{R}^{\mathrm{f} / \mathrm{fl}}$ (stock no. 022143) ${ }^{60}$, Eomes ${ }^{\mathrm{f} / \mathrm{fl}}$ (stock no. $017293)^{61}$, and IL-15R $\alpha^{-l-}$ mice (stock no. 003723) ${ }^{31}$ including appropriate control mice were purchased from The Jackson Laboratory. Whenever possible, control littermates were used and cohoused (age 8-16 weeks). Both sexes were considered equally. Experimental procedures were approved by the relevant animal experimentation committee and performed in compliance with international and local animal welfare legislations (Landesverwaltungsamt Sachsen-Anhalt, permit numbers AZ 42502-2-1202 and AZ 42502-2-1521 Uni MD).

Cell isolation. Mice were used euthanized by isoflurane inhalation overdose. Single-cell suspensions of spleen were prepared by forcing the organs through metal sieves. BM leukocytes were flushed from tibia, femur, and coxal bone using PBS/2 mM EDTA (ROTH). To lyse erythrocytes, cell suspensions were incubated with ACK lysis buffer for $90 \mathrm{~s}$ and subsequent addition of RPMI 1640 (Biochrome) with 10\% FCS (PAN Biotech). Cells resuspended in PBS/2 mM EDTA were filtered through $40 \mu \mathrm{m}$ cell strainers (Corning, Durham, NC, USA).

LPL were isolated from different parts of the intestine according to published protocols ${ }^{2,62}$. Briefly, residual mesenteric fat and Peyer's Patches were carefully removed. Intestinal tissue was opened longitudinally and washed two to three times in ice-cold PBS with $100 \mathrm{U} / \mathrm{ml}$ penicillin/streptomycin (P/S; GIBCO Life

Technologies). The epithelial layer and containing intraepithelial leukocytes were removed by two incubation steps in Hank's balanced salt solution without $\mathrm{Ca}^{2+}$ and $\mathrm{Mg}^{2+}$ (HBSS; Biochrom) supplemented with $5 \mathrm{mM}$ EDTA, $10 \mathrm{mM}$ HEPES and $\mathrm{P} / \mathrm{S}$ for $20 \mathrm{~min}$ at RT with slow rotation $(100 \mathrm{rpm})$ and subsequent vortexing 

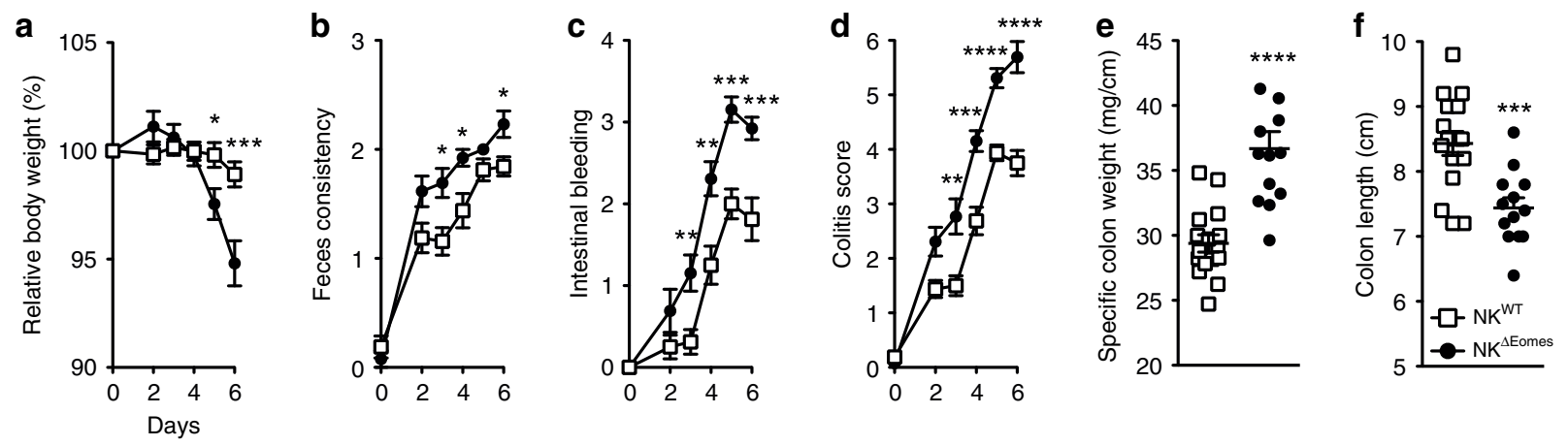

h
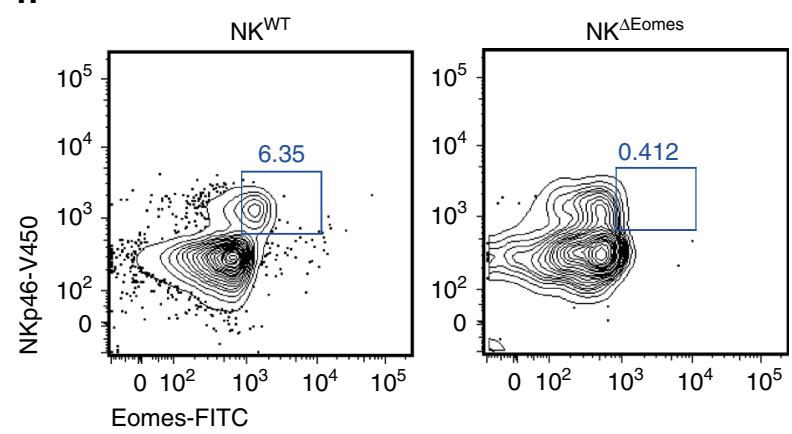

i

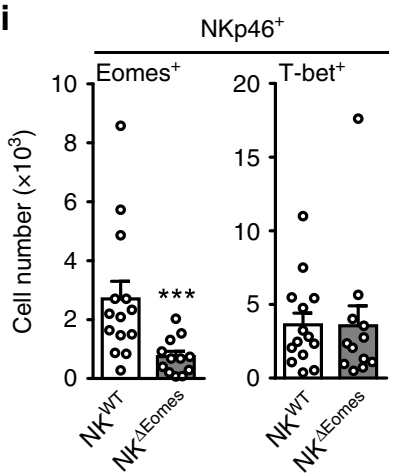

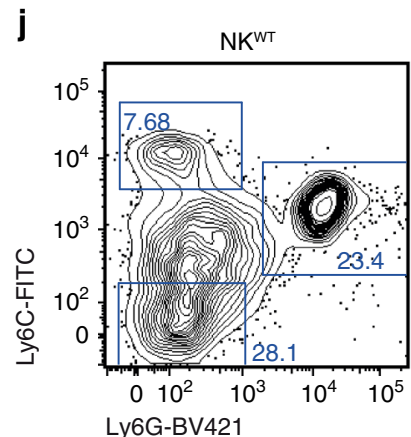
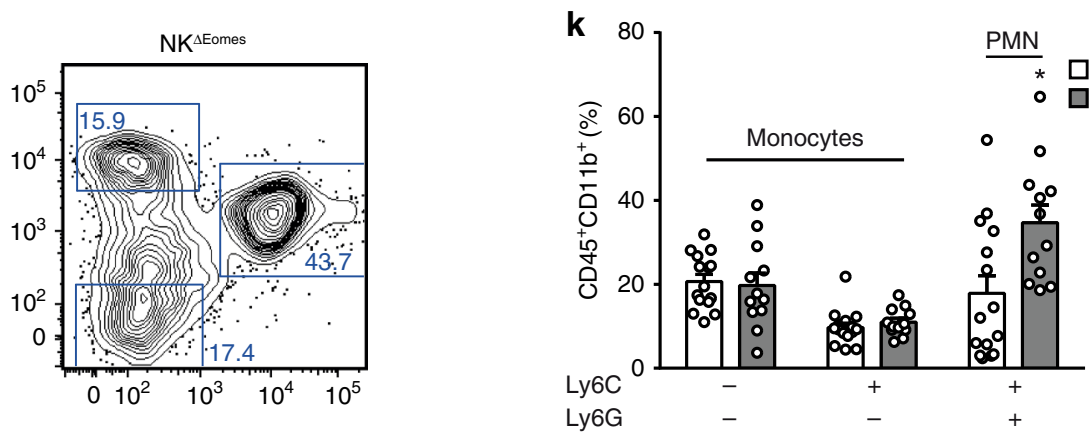

Fig. 8 Conventional NK cells ameliorate acute colitis. a-k NKWT and NK $\Delta$ Eomes mice were treated with DSS for 5 days as described in Fig. 4 . a Relative body weight, $\mathbf{b}$ feces consistency, and $\mathbf{c}$ the degree of intestinal bleeding were measured on a daily basis to calculate $\mathbf{d}$ the overall colitis score. $\mathbf{e}-\mathbf{g}$ At day 7, e the specific weight and $\mathbf{f}, \mathbf{g}$ the length of the colon were determined. $\mathbf{g}$ Shown are representative photographs of colon and cecum (scale unit $=\mathrm{cm}$ ). h, i Colonic lamina propria leukocytes were analyzed by flow cytometry at day 7. Frequencies of $\mathrm{Lin}^{-} \mathrm{CD}_{4} 5^{+} \mathrm{NKp} 46^{+} \mathrm{ILC1}\left(\mathrm{T}-\mathrm{bet}{ }^{+}\right)$and cNK $\left(\right.$Eomes $\left.{ }^{+}\right)$ and $\mathbf{j}, \mathbf{k}$ CD $45^{+} \mathrm{CD} 11 \mathrm{~b}^{+} \mathrm{Ly} 6 \mathrm{C}^{+/} /-\mathrm{Ly} 6 \mathrm{G}-$ monocyctes as well as Ly6C+Ly6G+ neutrophils (PMN) were determined by flow cytometry. $\mathbf{i}$ Absolute cell numbers were calculated. $\mathbf{h}, \mathbf{j}$ Representative contour plots are shown. Numbers indicate percentages. $\mathbf{a}-\mathbf{f}, \mathbf{i}$ and $\mathbf{k}$ Data were pooled from two independent experiments with a total of 12-16 mice per group. Data show means $+/ \pm$ SEM. Source data are provided as source data file; ${ }^{*} p \leq 0.05 ;{ }^{\star \star} p \leq 0.005 ;$ ${ }^{\star \star \star} p \leq 0.001 ;{ }^{\star \star \star \star} p \leq 0.0001$ (two-tailed Mann-Whitney $U$ test). i, k 12-15 tissue samples were analyzed.

for $15 \mathrm{~s}$. Tissue pieces were washed in PBS P/S, minced and incubated 2-3 times for $20 \mathrm{~min}$ at $37^{\circ} \mathrm{C}$ in digestion solution containing $4 \%$ FCS, $0.25 \mathrm{mg} / \mathrm{ml} \mathrm{each}$ of collagenase D (Roche), DNaseI (Sigma-Aldrich), and Dispase II (Roche) followed by vigorous vortexing and passage through $40 \mu \mathrm{m}$ cell strainers. Leukocytes were enriched by density gradient centrifugation at $600 \times g$ for $20 \mathrm{~min}$ at RT.

Flow cytometry. The following reagents were purchased from BioLegend or eBiosciences: anti-mouse CD3 (145-2C11), CD4 (RM4-5), CD5 (53-7.3), CD8a (53-6.7), CD11b (M1/70), CD11c (N418), CD19 (1D3), CD45 (30-F11), CD120a (TNF-RI; 55R-286), CD122 (TM- $\beta 1$ ), Eomes (Dan11mag), F4/80 (BM8), GM-CSF (MP1-22E9), IFN- $\gamma$ (XMG1.2), Ly6C/G/Gr-1 (RB6-8C5), Ly6G/Gr1 (1A8), Ly6C (HK1.4), MCP-1 (2H5), NK1.1 (PK136), T-bet (4B10), Ter119 (TER-119), TNF (MP6-XT22), TRAIL (N2B2), armenian hamster IgG1 (RTK2073), donkey-antirabbit IgG (Poly4064), rat IgG1, к (RTK2071), rat IgG2a, к (RTK2758), and Zombie viability dye. Anti-mouse CD16/32 (2.4G2; ATCC ${ }^{\oplus}$ HB-197 $\left.{ }^{\mathrm{DN}}\right)$ was produced in our laboratory. Anti-mouse CD11b (M1/70), GATA-3 (TWAJ), NKp46 (29A14), pSTAT5 pY694 (47/Stat5), ROR $\gamma t$ (B2D), and Streptavidin-FITC were purchased from BD Biosciences. Polyclonal rabbit-anti-c-FLIP was purchased from Abcam. Anti-mouse Ly49A (A1), Ly49C/I (REA253), and Eomes (REA116) were purchased from Miltenyi Biotec. Further antibody information is provided in Supplementary Table 1 .

Single cell suspensions of spleen, BM as well as LPL were stained with fluorochrome-labeled antibodies for $30 \mathrm{~min}$ at $4{ }^{\circ} \mathrm{C}$ after blocking Fc receptors with anti-CD16/32. For detection of cytoplasmic antigens, cells were incubated in fixation buffer (BioLegend) for $30 \mathrm{~min}$ at $4{ }^{\circ} \mathrm{C}$, permeabilized and stained with the appropriate antibodies in permeabilization wash buffer (BioLegend) for $30 \mathrm{~min}$ at $4{ }^{\circ} \mathrm{C}$. For staining of nuclear antigens, cells were permeabilized and fixed using the Foxp3 staining buffer set (eBioscience) according to the manufacturer's instructions. Peripheral blood leukocytes were stained in whole blood samples for $30 \mathrm{~min}$ at RT, followed by erythrocyte lysis and fixation using BD FACS TM lysing solution (BD Biosciences). Samples were measured on a LSR Fortessa and FACSCanto flow cytometer (Becton Dickinson) and analyzed by FlowJo software (FlowJo LLC).

In vitro stimulation of splenic ILC. Splenocytes were isolated from C57BL/6 mice and cultured for $16 \mathrm{~h}$ in RPMI (with $10 \%$ FCS and $100 \mathrm{U} / \mathrm{ml} \mathrm{P/S}$ ) supplemented with IL-15 (10 ng/ml, Peprotech), with rmIL-15 $(10 \mathrm{ng} / \mathrm{ml})$ and pimozide $(5 \mu \mathrm{M}$, Calbiochem) or were left untreated. Lineage negative $\left(\mathrm{CD} 3^{-}, \mathrm{CD} 4^{-}, \mathrm{CD} 8^{-}, \mathrm{CD} 19^{-}\right.$, 
$\mathrm{Gr1}^{-}$, Ter119- $) \mathrm{CD} 122^{+} \mathrm{NK} 1.1^{+} \mathrm{NKp} 46^{+}$ILC were analyzed by flow cytometry for their expression of c-FLIP and phosphorylation of STAT5.

Detection of apoptotic cells. Apoptotic cells were visualized by flow cytometry by using the FAM-FLICA Caspase 3/7 assay kit from ImmunoChemistry Technologies according to the manufacturer's protocol. The cell permeable, fluorescent inhibitor probe FAM-DEVD-FMK irreversibly binds to active caspases 3 and 7 .

In vitro culture of ILC precursors. BM-derived ILC precursors were enriched by depletion of Ter119 ${ }^{-}, \mathrm{CD}_{19}^{-}$, and LyG/Gr1-positive cells using the respective biotinylated antibodies (Ter119, CD19, and Ly6G/Gr1; clones as indicated above) and anti-biotin Dynabeads (Invitrogen) according to the manufacturer's recommendations. Next, the Ter119/CD19/Gr1-depleted cell suspension was labeled with antibodies against CD3, CD4, CD8, CD122, and NK1.1 and FITC-conjugated streptavidin. Lineage negative (Ter119 ${ }^{-}, \mathrm{CD}^{-}{ }^{-}, \mathrm{Ly}_{6 \mathrm{G}} / \mathrm{Gr}^{-}, \mathrm{CD}^{-}, \mathrm{CD}^{-}, \mathrm{CD}^{-}$) $\mathrm{CD} 122^{+} \mathrm{NK} 1.1^{-}$BM ILC precursors were enriched (on average $42 \%$ ) by fluorescence-activated cell sorting (FACS Vantage DIVA, FACS Aria III, Becton Dickinson). ILC precursors were co-cultured with irradiated (4 Gy) OP9 cells (ATCC ${ }^{\circledR}$ CRL-2749 ${ }^{\mathrm{m}}$ ) in a-MEM medium (GIBCO Life Technologies) containing 10\% FCS, 20 ng/ml SCF (Peprotech), 20 ng/ml Flt-3 ligand (Peprotech), 20 ng/ml IL-7 (eBioscience), $20 \mathrm{ng} / \mathrm{ml}$ IL-15 (Peprotech), $150 \mu \mathrm{M}$ 1-thioglycerol (SigmaAldrich), $2 \mathrm{mM}$ L-glutamine (GIBCO Life technologies), $1 \mathrm{mM}$ Na-pyruvate (GIBCO Life technologies), $100 \mathrm{U} / \mathrm{ml}$ penicillin/streptomycin, and 1 x primocin (Amaxa) for 9 days. After 4 days of co-culture, $50 \%$ of medium was replaced. Two days later cells were moved to a fresh OP9 feeder cell layer. At day 9 of co-culture cells were analyzed by flow cytometry. To block TNF-, FASL- or TRAIL-mediated signaling, $10 \mu \mathrm{g} / \mathrm{ml}$ of anti-TNF (MP6-XT22), anti-FASL (3C82; Enzo), or antiTRAIL (N2B2), respectively, were added to the co-cultures every 2.5 days. Isotypematched control antibodies were used as controls. Blocking/control reagents were purchased from BioLegend.

Quantitative real-time PCR (RT-qPCR). FACS-sorted splenic ILC (CD3 ${ }^{-} \mathrm{NKp} 46^{+}$ $\left.\mathrm{NK} 1.1^{+}\right)$were stimulated with IL-15 $(50 \mathrm{ng} / \mathrm{ml})$ for $16 \mathrm{~h}$ or were left untreated. ILC progenitors were sorted using MoFlo Sorter (Beckman Coulter) from BM extracts. RNA isolation from cell cultures and primary cells was performed using QIAshredder and RNeasy Mini Kit (QIAGEN) according to manufacturer's protocol. cDNA was synthetized using the cDNA Synthesis Kit (Life technologies) according to manufacturer's instructions. The cDNA served as a template for the amplification by realtime PCR, using SYBR Green (Roche) in a LightCycler 96 instrument (Roche). Ubiquitin-conjugating enzyme E2D 2A (UCE) was used as reference gene. Primers: UCE fwd: 5' -AAGAGAATCCACAAGGAATTGAATG-3'; UCE rev: 5'-CAACA GGACCTGCTGA ACACTG-3'. CD95 (FAS) fwd: 5'-GCAGACAUGCUGUGGA UCUG-3; CD95 (FAS) rev: 5' -UCGGAGAUGCUAUUAGUACCUUGAG-3. DR5 (TRAIL-R2) fwd: 5'-CCCUGAGAUCUGCCAGUCAU-3'; DR5 (TRAIL-R2) rev: 5' UGGGGGUACAGGAAGUCAGU-3'. TNF-R1 fwd: 5'-GAAAGUAUGUCCAUUC UAAGAACAA-3'; TNF-R1 rev: 5'-AGUCACUCACCAAGUAGGUUCCUU-3' . cFLIP $_{\mathrm{L}}$ fwd: $5^{\prime}$-GCAGAAGCUCUCCCAGCA-3; c-FLIP ${ }_{\mathrm{L}}$ rev: 5'-UUUGUCCAUGAG UUCAACGUG-3' ${ }^{\prime}$ c c-FLIP ${ }_{\mathrm{R}}$ fwd: 5'-UCCAGAAGUACACCCAGUCCA-3'; c-FLIP ${ }_{\mathrm{R}}$ rev: 5'-CACUGGCUCCAGACUCACC- ${ }^{\prime}$.

DSS-induced colitis. Acute colitis was induced by administration of 1.8-2.5\% (w/v) dextran sulfate sodium (DSS; MW 36,000-50,000; ICN Biomedicals) ad libitum via the drinking water for 5 consecutive days. Chronic colitis was induced by repeated DSS administration (1.6\%) for 5 days interrupted by 14-day periods on normal drinking water. Total body weight and feces samples were monitored. Feces consistency was evaluated to determine the degree of diarrhea. Furthermore, feces samples were analyzed for occult blood to determine the degree of intestinal bleeding. Occult blood was detected using hemoCARE test (Care diagnostic). Disease activity score was calculated by summarizing the scores for weight loss, feces consistency, and bleeding ${ }^{63}$.

Histological analysis. Tissue samples from distal, medial, and proximal colon $(0.5-1 \mathrm{~cm})$ were fixed in $4 \%$ formalin and embedded in paraffin. $1-2 \mu \mathrm{m}$-thick sections were cut, dewaxed, and histochemically stained with hematoxylin \& eosin (Merck). Histomorphological changes were evaluated in (HE)-stained tissue sections and images (original magnification $\times 100$ ) were taken by standard light microscopy using an AxioImager Z1 microscope (Carl Zeiss MicroImaging, Jena, Germany). Histopathological evaluation was performed in a blinded manner using a standardized histologic score ranging from 0 to $6^{64}$.

Analysis of colonic cytokine production. Samples of $\sim 1 \mathrm{~cm}$ in length were isolated from the proximal, medial, and distal part of each colon. Samples were cleaned, opened longitudinally, and weighed. These colonic tissue explants were cultured in $500 \mu \mathrm{l}$ complete RPMI 1640 supplemented with $2 \%$ FCS and $100 \mathrm{U} / \mathrm{ml}$ $\mathrm{P} / \mathrm{S}$ in 24 -well flat-bottom plates at $37^{\circ} \mathrm{C} / 5 \% \mathrm{CO}_{2}$ for $24 \mathrm{~h}$. Culture supernatants were harvested and subsequently centrifuged at $10,000 \times g$ for $10 \mathrm{~min}$ to remove debris. Supernatants were stored at $-80^{\circ} \mathrm{C}$. Cytokine levels were measured using the Legendplex Mouse inflammation panel (Biolegend) or IL-22-ELISA
(Affimetrix/eBioscience) according to the manufacturer's instructions. Cytokine levels were normalized to tissue mass and expressed as picogram of cytokine per microgram of tissue. Normalized cytokine data from the three colonic tissue explants per mouse were pooled.

For the flow cytometric analysis of cytokine production, colon samples from 2 to 3 mice were pooled, LPL were enriched and cultured subsequently for $5 \mathrm{~h}$ in the presence of $20 \mathrm{ng} / \mathrm{ml}$ phorbol myristate acetate (PMA) $/ 1 \mu \mathrm{g} / \mathrm{ml}$ ionomycin. Brefeldin A (BD GolgiPlug TM; BD Biosciences) was added for the last $4 \mathrm{~h}$ of culture. Stimulated LPL were washed and incubated with fluorochrome-labeled antibodies for $30 \mathrm{~min}$ at $4{ }^{\circ} \mathrm{C}$ in the dark. After washing, LPL were fixed using the Fixation buffer for intracellular staining procedures (Biolegend) for $15 \mathrm{~min}$ in the dark at RT. Samples were washed with PBS/2 mM EDTA and stored in PBS/0.5\% (w/v) BSA/2 mM EDTA containing anti-CD16/32 overnight. Subsequently, cells were washed in $200 \mu$ l permeabilization buffer (Biolegend) and incubated with fluorochome-labeled anti-cytokine mAbs or isotype-matched control antibodies for $1 \mathrm{~h}$ at $4^{\circ} \mathrm{C}$. After washing cells were resuspended in PBS/ $2 \mathrm{mM}$ EDTA, measured on a LSR Fortessa (Becton Dickinson) flow cytometer and analyzed by FlowJo software (FlowJo LLC)

NK depletion. C57BL/6 mice were injected i.p. with $50 \mu \mathrm{g}$ of NK-depleting antiAsialo GM1 (Affimetrix). Treatment was repeated every third day. A total of four injections were performed. Control animals were treated accordingly with $50 \mu \mathrm{g}$ polyclonal rabbit control IgG (Sigma-Aldrich).

Statistical analysis. Experimental results were plotted and analyzed for statistical significance with Prism software 5 or 6 (GraphPad Software Inc.). Statistical significances were determined using two-tailed Mann-Whitney $U$ test, paired and unpaired Student's $t$ test or two-tailed Wilcoxon matched-pairs signed rank test $\left({ }^{*} p \leq 0.05 ;{ }^{* *} p \leq 0.005 ;{ }^{* * *} p \leq 0.001 ;{ }^{* * *} p \leq 0.0001\right)$. Exact $p$ values are provided in Source data.

DNA isolation. Feces samples were collected and stored at $-20^{\circ} \mathrm{C}$ until processing for DNA-based 16S rRNA gene sequencing. DNA was extracted using an established phenol-chloroform-based method ${ }^{65}$. In short, $500 \mu \mathrm{l}$ of extraction buffer (200 mM Tris (Roth), $20 \mathrm{mM}$ EDTA (Roth), $200 \mathrm{mM} \mathrm{NaCl}$ (Roth), pH 8.0), $200 \mu \mathrm{l}$ of $20 \%$ SDS (AppliChem), $500 \mu$ of phenol:chloroform:isoamyl alcohol (PCI) (24:24:1) (Roth) and $100 \mu \mathrm{l}$ of zirconia/silica beads ( $0.1 \mathrm{~mm}$ diameter) (Roth) were added to each feces sample. Samples were lysed and homogenized twice using a Mini-BeadBeater-96 (BioSpec) for 2 min. After centrifugation and additional extraction with PCI (24:24:1), DNA was precipitated using $500 \mu \mathrm{l}$ isopropanol (J.T Baker) and 0.1 volume of $3 \mathrm{M}$ sodium acetate (AppliChem). Samples were incubated at $-20^{\circ} \mathrm{C}$ overnight and centrifuged at $4{ }^{\circ} \mathrm{C}$ at maximum speed for $20 \mathrm{~min}$. The resulting DNA pellet was dried, resuspended in TE buffer (AppliChem) with $100 \mu \mathrm{g} / \mathrm{ml}$ RNase I (Sigma-Aldrich) and column purified (BioBasic Inc.) to remove PCR inhibitors.

16S rRNA gene amplification and sequencing. 16S rRNA gene amplification of the V4 region (F515/R806) was performed according to an established protocol previously described ${ }^{40}$. Briefly, DNA was normalized to $25 \mathrm{ng} / \mu \mathrm{l}$ and used for sequencing PCR with unique 12-base Golary barcodes incorporated via specific primers (obtained from Sigma-Aldrich). Using Q5 polymerase (New England Biolabs), PCR was performed in triplicates for each sample, using PCR conditions of initial denaturation for $30 \mathrm{~s}$ at $98^{\circ} \mathrm{C}$, followed by 25 cycles $\left(10 \mathrm{~s}\right.$ at $98^{\circ} \mathrm{C}, 20 \mathrm{~s}$ at $55^{\circ} \mathrm{C}$, and $20 \mathrm{~s}$ at $72^{\circ} \mathrm{C}$ ). After pooling and normalization to $10 \mathrm{nM}$, PCR amplicons were sequenced on an Illumina MiSeq platform via $250 \mathrm{bp}$ paired-end sequencing (PE250).

16S rRNA gene analysis. Using Usearch8.1 software package (http://www.drive5. com/usearch/) the resulting reads were assembled, filtered, and clustered. In brief, merging was performed using -fastq_mergepairs -with fastq_maxdiffs 30 and quality controlling was performed with fastq_filter (-fastq_maxee 1), using a minimum read length of $200 \mathrm{bp}$ and a minimum number of sequences per sample $=1000$ as thresholds. Reads were clustered into 97\% ID OTUs and representative sequences were determined by use of UPARSE algorithm ${ }^{66}$. Taxonomy classification was performed with the Silva database $v 128^{67}$ and the RDP Classifier executed at $80 \%$ bootstrap confidence ${ }^{68}$. Resulting OTU absolute abundance table and mapping file were used for statistical analyses and data visualization using $\mathrm{R}$ statistical programming environment (R Core Team (2016)) package phyloseq ${ }^{69}$.

Statistics were performed with 'R' version 3.3.0 (2016-05-03), (http://www. rproject.org) and the packages 'phyloseq' ${ }^{69}$, and 'ggplot 2 '70. Non-parametric Mann-Whitney $U$ tests were considered as significant when $P$ values were lower than 0.05 after multiple testing correction (Benjamini-Hochberg false discovery rate correction). Permutational multivariate analysis of variance test (ADONIS) was used to assess the influence of different variables on the sample variability. The ADONIS tests were computed using 999 permutations and a resulting $R^{2}>0.1$ (effect size $10 \%$ ) and $P$-values $<0.05$ were considered as significant. LDA effect size (LEfSe) method was used to identify bacterial OTUs that explained differences between microbiota compositions ${ }^{41}$. Only OTUs with Kruskal-Wallis test $<0.05$ and LDA scores $>3.0$ were considered for analysis. 
Reporting summary. Further information on research design is available in the Nature Research Reporting Summary linked to this article.

\section{Data availability}

16S rRNA gene sequencing data have been deposited in the NCBI (Bioproject Database) under the accession number: PRJNA437582. The source data underlying Figs. 1a-d, 2a-f, $3 e-k, 4 a-f$ and $\mathrm{i}-\mathrm{m}, 5 \mathrm{a}-\mathrm{c}$, and $\mathrm{e}-\mathrm{h}, 6 \mathrm{a}-\mathrm{f}, 7 \mathrm{c}$ and $\mathrm{d}, 8 \mathrm{a}-\mathrm{f}$, $\mathrm{i}$ and $\mathrm{k}$ and Supplementary Figs. 1, 2, 3a, and e, 4a and e-k are provided as a Source Data file. All other data that support the findings of this study are available from the corresponding author on reasonable request.

Received: 9 April 2018; Accepted: 24 January 2020;

Published online: 26 February 2020

\section{References}

1. Spits, H. et al. Innate lymphoid cells-a proposal for uniform nomenclature. Nat. Rev. Immunol. 13, 145-149 (2013).

2. Klose, C. S. N. et al. Differentiation of type 1 ILCs from a common progenitor to all helper-like innate lymphoid cell lineages. Cell 157, 340-356 (2014).

3. Long, E. O., Kim, H. S., Liu, D., Peterson, M. E. \& Rajagopalan, S. Controlling natural killer cell responses: integration of signals for activation and inhibition. Annu. Rev. Immunol. 31, 227-258 (2013).

4. Moro, $\mathrm{K}$. et al. Innate production of $\mathrm{T}(\mathrm{H}) 2$ cytokines by adipose tissueassociated c-Kit(+)Sca-1(+) lymphoid cells. Nature 463, 540-544 (2010).

5. Satoh-Takayama, N. et al. Microbial flora drives interleukin 22 production in intestinal NKp46+ cells that provide innate mucosal immune defense. Immunity 29, 958-970 (2008).

6. Sonnenberg, G. F., Fouser, L. A. \& Artis, D. Border patrol: regulation of immunity, inflammation and tissue homeostasis at barrier surfaces by IL-22. Nat. Immunol. 12, 383-390 (2011).

7. Lindemans, C. A. et al. Interleukin-22 promotes intestinal-stem-cell-mediated epithelial regeneration. Nature 528, 560-564 (2015).

8. Sawa, S. et al. ROR $\gamma \mathrm{t}+$ innate lymphoid cells regulate intestinal homeostasis by integrating negative signals from the symbiotic microbiota. Nat. Immunol. 12, 320-326 (2011).

9. Rankin, L. C. et al. Complementarity and redundancy of IL-22-producing innate lymphoid cells. Nat. Immunol. 17, 179-186 (2016).

10. Song, C. et al. Unique and redundant functions of NKp46+ ILC3s in models of intestinal inflammation. J. Exp. Med. 212, 1869-1882 (2015).

11. Vély, F. et al. Evidence of innate lymphoid cell redundancy in humans. Nat. Immunol. 17, 1291-1299 (2016).

12. Klose, C. S. \& Diefenbach, A. Transcription factors controlling innate lymphoid cell fate decisions. Curr. Top. Microbiol. Immunol. 381, 215-255 (2014).

13. Rochman, Y., Spolski, R. \& Leonard, W. J. New insights into the regulation of T cells by gamma(c) family cytokines. Nat. Rev. Immunol. 9, 480-490 (2009).

14. Satoh-Takayama, N. et al. IL-7 and IL-15 independently program the differentiation of intestinal CD3-NKp46+ cell subsets from Id2-dependent precursors. J. Exp. Med. 207, 273-280 (2010).

15. Huntington, N. D. et al. Interleukin 15-mediated survival of natural killer cells is determined by interactions among Bim, Noxa and Mcl-1. Nat. Immunol. 8, 856-863 (2007).

16. Link, A. et al. Fibroblastic reticular cells in lymph nodes regulate the homeostasis of naive T cells. Nat. Immunol. 8, 1255-1265 (2007).

17. Gil-Cruz, C. et al. Fibroblastic reticular cells regulate intestinal inflammation via IL-15-mediated control of group 1 ILCs. Nat. Immunol. 17, 1388-1396 (2016).

18. Shalapour, S. et al. Interleukin-7 links T lymphocyte and intestinal epithelial cell homeostasis. PLoS One 7, e31939 (2012).

19. Narni-Mancinelli, E. et al. Fate mapping analysis of lymphoid cells expressing the NKp46 cell surface receptor. Proc. Natl Acad. Sci. USA 108, 18324-18329 (2011).

20. Irmler, M. et al. Inhibition of death receptor signals by cellular FLIP. Nature 388, 190-195 (1997).

21. Chau, H. et al. Cellular FLICE-inhibitory protein is required for T cell survival and cycling. J. Exp. Med. 202, 405-413 (2005).

22. Panayotova-Dimitrova, D. et al. cFLIP regulates skin homeostasis and protects against TNF-induced keratinocyte apoptosis. Cell Rep. 5, 397-408 (2013).

23. Zhang, N. \& He, Y.-W. An essential role for c-FLIP in the efficient development of mature T lymphocytes. J. Exp. Med. 202, 395-404 (2005).

24. Ueffing, N., Schuster, M., Keil, E., Schulze-Osthoff, K. \& Schmitz, I. Upregulation of c-FLIP short by NFAT contributes to apoptosis resistance of short-term activated T cells. Blood 112, 690-698 (2008).
25. Kennedy, M. K. et al. Reversible defects in natural killer and memory CD8 T cell lineages in interleukin 15-deficient mice. J. Exp. Med. 191, 771-780 (2000).

26. Fuchs, A. et al. Intraepithelial type 1 innate lymphoid cells are a unique subset of IL-12- and IL-15-responsive IFN- $\gamma$-producing cells. Immunity 38, 769-781 (2013).

27. Ueffing, N. et al. Mutational analyses of c-FLIPR, the only murine short FLIP isoform, reveal requirements for DISC recruitment. Cell Death Differ. 15, 773-782 (2008).

28. Carson, W. E. et al. A potential role for interleukin-15 in the regulation of human natural killer cell survival. J. Clin. Invest. 99, 937-943 (1997).

29. Ebbo, M., Crinier, A., Vély, F. \& Vivier, E. Innate lymphoid cells: major players in inflammatory diseases. Nat. Rev. Immunol. 17, 665-678 (2017)

30. Mirandola, P. et al. Activated human NK and CD8 + T cells express both TNF-related apoptosis-inducing ligand (TRAIL) and TRAIL receptors but are resistant to TRAIL-mediated cytotoxicity. Blood 104, 2418-2424 (2004).

31. Lodolce, J. P. et al. IL-15 receptor maintains lymphoid homeostasis by supporting lymphocyte homing and proliferation. Immunity 9, 669-676 (1998).

32. Robinette, M. L. et al. IL-15 sustains IL-7R-independent ILC2 and ILC3 development. Nat. Commun. 8, 14601 (2017).

33. Wirtz, S., Neufert, C., Weigmann, B. \& Neurath, M. F. Chemically induced mouse models of intestinal inflammation. Nat. Protoc. 2, 541-546 (2007).

34. Kaser, A., Zeissig, S. \& Blumberg, R. S. Inflammatory bowel disease. Annu. Rev. Immunol. 28, 573-621 (2010).

35. Eftychi, C. et al. Temporally distinct functions of the cytokines IL-12 and IL23 drive chronic colon inflammation in response to intestinal barrier impairment. Immunity 51, 367-380.e4 (2019).

36. Egea, L. et al. GM-CSF produced by nonhematopoietic cells is required for early epithelial cell proliferation and repair of injured colonic mucosa. $J$. Immunol. 190, 1702-1713 (2013).

37. Blander, J. M., Longman, R. S., Iliev, I. D., Sonnenberg, G. F. \& Artis, D. Regulation of inflammation by microbiota interactions with the host. Nat. Immunol. 18, 851-860 (2017).

38. Levy, M., Kolodziejczyk, A. A., Thaiss, C. A. \& Elinav, E. Dysbiosis and the immune system. Nat. Rev. Immunol. 17, 219-232 (2017).

39. Roy, U. et al. Distinct microbial communities trigger colitis development upon intestinal barrier damage via innate or adaptive immune cells. Cell Rep. 21, 994-1008 (2017).

40. Caporaso, J. G. et al. Global patterns of $16 \mathrm{~S}$ rRNA diversity at a depth of millions of sequences per sample. Proc. Natl Acad. Sci. USA 108(Suppl. 1), 4516-4522 (2011)

41. Segata, N. et al. Metagenomic biomarker discovery and explanation. Genome Biol. 12, R60 (2011).

42. Zackular, J. P. et al. The gut microbiome modulates colon tumorigenesis. MBio 4, e00692-13 (2013).

43. Sonnenberg, G. F. et al. Innate lymphoid cells promote anatomical containment of lymphoid-resident commensal bacteria. Science 336 1321-1325 (2012)

44. Pikovskaya, O. et al. Cutting edge: eomesodermin is sufficient to direct Type 1 Innate lymphocyte development into the conventional NK lineage. $J$. Immunol. 196, 1449-1454 (2016)

45. Kwong, B. et al. T-bet-dependent $\mathrm{NKp} 46^{+}$innate lymphoid cells regulate the onset of $\mathrm{T}_{\mathrm{H}} 17$-induced neuroinflammation. Nat. Immunol. 18, 1117-1127 (2017).

46. Weizman, O. E. et al. ILC1 confer early host protection at initial sites of viral infection. Cell 171, 795-808.e12 (2017).

47. Vonarbourg, C. \& Diefenbach, A. Multifaceted roles of interleukin-7 signaling for the development and function of innate lymphoid cells. Semin. Immunol. 24, 165-174 (2012)

48. Marçais, A. et al. The metabolic checkpoint kinase mTOR is essential for IL-15 signaling during the development and activation of NK cells. Nat. Immunol. 15, 749-757 (2014)

49. Hall, L. J. et al. Natural killer cells protect mice from DSS-induced colitis by regulating neutrophil function via the NKG2A receptor. Mucosal Immunol. 6, 1016-1026 (2013)

50. Rapaport, A. S. et al. The inhibitory receptor NKG2A sustains virus-specific $\mathrm{CD}^{+} \mathrm{T}$ cells in response to a lethal poxvirus infection. Immunity 43, $1112-1124$ (2015)

51. Hall, L. J. et al. Induction and activation of adaptive immune populations during acute and chronic phases of a murine model of experimental colitis. Dig. Dis. Sci. 56, 79-89 (2011).

52. Shaul, M. E. \& Fridlender, Z. G. Neutrophils as active regulators of the immune system in the tumor microenvironment. J. Leukoc. Biol. 102, 343-349 (2017).

53. Bronte, V. et al. Recommendations for myeloid-derived suppressor cell nomenclature and characterization standards. Nat. Commun. 7, 12150 (2016)

54. Katoh, H. et al. CXCR2-expressing myeloid-derived suppressor cells are essential to promote colitis-associated tumorigenesis. Cancer Cell 24, 631-644 (2013). 
55. Neurath, M. F. Targeting immune cell circuits and trafficking in inflammatory bowel disease. Nat. Immunol. 20, 970-979 (2019).

56. Cui, Y. et al. Inactivation of Stat5 in mouse mammary epithelium during pregnancy reveals distinct functions in cell proliferation, survival, and differentiation. Mol. Cell Biol. 24, 8037-8047 (2004).

57. Reinhardt, R. L., Liang, H.-E. \& Locksley, R. M. Cytokine-secreting follicular T cells shape the antibody repertoire. Nat. Immunol. 10, 385-393 (2009).

58. Mombaerts, P. et al. RAG-1-deficient mice have no mature B and T lymphocytes. Cell 68, 869-877 (1992).

59. Peschon, J. J. et al. Early lymphocyte expansion is severely impaired in interleukin 7 receptor-deficient mice. J. Exp. Med 180, 1955-1960 (1994).

60. McCaughtry, T. M. et al. Conditional deletion of cytokine receptor chains reveals that IL-7 and IL-15 specify CD8 cytotoxic lineage fate in the thymus. J. Exp. Med 209, 2263-2276 (2012).

61. Zhu, Y. et al. T-bet and eomesodermin are required for T cell-mediated antitumor immune responses. J. Immunol. 185, 3174-3183 (2010).

62. Sanos, S. L. \& Diefenbach, A. Isolation of NK cells and NK-like cells from the intestinal lamina propria. Methods Mol. Biol. 612, 505-517 (2010).

63. Bank, U. et al. Triggering endogenous immunosuppressive mechanisms by combined targeting of Dipeptidyl peptidase IV (DPIV/CD26) and Aminopeptidase N (APN/ CD13)-a novel approach for the treatment of inflammatory bowel disease. Int Immunopharmacol. 6, 1925-1934 (2006).

64. Erben, U. et al. A guide to histomorphological evaluation of intestinal inflammation in mouse models. Int J. Clin. Exp. Pathol. 7, 4557-4576 (2014).

65. Turnbaugh, P. J. et al. A core gut microbiome in obese and lean twins. Nature 457, 480-484 (2009).

66. Edgar, R. C. UPARSE: highly accurate OTU sequences from microbial amplicon reads. Nat. Methods 10, 996-998 (2013).

67. Quast, C. et al. The SILVA ribosomal RNA gene database project: improved data processing and web-based tools. Nucleic Acids Res 41, D590-D596 (2013).

68. Wang, Q., Garrity, G. M., Tiedje, J. M. \& Cole, J. R. Naive Bayesian classifier for rapid assignment of rRNA sequences into the new bacterial taxonomy. Appl Environ. Microbiol 73, 5261-5267 (2007).

69. McMurdie, P. J. \& Holmes, S. phyloseq: an R package for reproducible interactive analysis and graphics of microbiome census data. PLoS One $\mathbf{8}$, e61217 (2013).

70. Wickham, H. ggplot2: elegant graphics for data analysis (Springer, 2016).

\section{Acknowledgements}

We thank E. Denks, J. Giese, C. Kozowsky, J. Nichelmann, S. Schumann, and M. Berger for excellent technical assistance. We are grateful to Dr. Y.-W. He for providing c-FLIPfl/fl mice. This work was supported by the Deutsche Forschungsgemeinschaft Sonderforschungsbereich SFB854 (project A22) and DFG priority program 1937 (project SCHU $2326 / 2-1)$.

\section{Author contributions}

A.A.K., I.R.D., T.S., I.S., and T.S. designed and supervised the study with the help of U.B and K.D.; U.B., K.D., C.P.-S., L.O., A.W., L.K., R.L., R.J., F.R., and A.B. performed the experiments and analyzed the data; A.C.Z., C.R., and E.V. provided essential reagents; T.S. wrote the manuscript with the help of the other co-authors.

\section{Competing interests}

The authors declare competing financial interests. The E.V. laboratory is supported by the European Research Council (ERC) under the "European Union's Horizon 2020 research and innovation program (Grant agreement no. 694502)", Agence Nationale de la Recherche, Innate Pharma, MSDAvenir, Ligue Nationale contre le Cancer (Equipe labelisée "La Ligue") and Marseille-Immunopole. E.V. is cofounder, shareholder, and employee of Innate Pharma.

\section{Additional information}

Supplementary information is available for this paper at https://doi.org/10.1038/s41467 020-14782-3.

Correspondence and requests for materials should be addressed to T.Sül.

Peer review information Nature Communications thanks Shigeo Koyasu and the other, anonymous, reviewer(s) for their contribution to the peer review of this work. Peer reviewer reports are available.

Reprints and permission information is available at http://www.nature.com/reprints

Publisher's note Springer Nature remains neutral with regard to jurisdictional claims in published maps and institutional affiliations.

\begin{abstract}
(c) (i) Open Access This article is licensed under a Creative Commons Attribution 4.0 International License, which permits use, sharing, adaptation, distribution and reproduction in any medium or format, as long as you give appropriate credit to the original author(s) and the source, provide a link to the Creative Commons license, and indicate if changes were made. The images or other third party material in this article are included in the article's Creative Commons license, unless indicated otherwise in a credit line to the material. If material is not included in the article's Creative Commons license and your intended use is not permitted by statutory regulation or exceeds the permitted use, you will need to obtain permission directly from the copyright holder. To view a copy of this license, visit http://creativecommons.org/ licenses/by/4.0/.
\end{abstract}

(C) The Author(s) 2020 